\title{
High-resolution prediction of American red squirrel in Interior Alaska: A role model for conservation using open access data, machine learning, GIS and LIDAR
}

\author{
Richard B Robold ${ }^{\text {Corresp., } 1}{ }^{1}$, Falk Huettmann ${ }^{1}$ \\ ${ }^{1}$ Institute of Arctic Biology, University of Alaska - Fairbanks, Fairbanks, Alaska, United States \\ Corresponding Author: Richard B Robold \\ Email address: rr@robold.info
}

American red squirrels (Tamiasciurus hudsonicus) are small mammals that are abundantly distributed throughout the North American continent. Urbanization in the Anthropocene is now a global process, and squirrels live in such landscapes. This leads to squirrels adjusting to human developments. Not much is known about the distribution of squirrels and squirrel middens near humans, especially not in the subarctic and sub-urbanized regions. Although this species is hunted, there are no real publicly available distribution and abundance estimates nor management plans and bag limits for squirrels in Alaska or in the United States known by us, except the endangered Mt. Graham squirrel. In general, insufficient squirrel conservation research is carried out; they are underrepresented in research and its literature. To further the science-based management for such species this study aims to generate a first and digital open access workflow as a generic research template for small mammal work including latest machine learning of open source and high-resolution LIDAR data in an Open Source Geographic Information System (QGIS) and ArcGIS. Machine learning has proven to be less modeler biased and improve accuracy of the analysis outcome so it is the preferred approach. This template is designed to be rapid, simple, robust, generic and effective for being used by a global audience. As a unique showcase, here a squirrel midden survey was carried out for two years (2016 and 2017).

These squirrel middens were detected in a research area of 45,5 hectares $\left(0,455 \mathrm{~km}^{2}\right)$ in downtown Fairbanks, interior boreal forest of Alaska, U.S. Transect distances were georeferenced with a GPS and adjusted to the visual conditions to count all squirrel middens within the survey area. Different layers of proximity to humans and habitat characteristics were assembled using aerial imagery and LIDAR data (3D data needed for an arboreal species like the red squirrels) consisting of a $3 \times 3 \mathrm{~m}$ resolution. The layer data was used to train a predictive distribution model for red squirrel middens with machine learning. The model showed the relative index of occurrence (RIO) in a map and identified canopy 
height, distance to trails, canopy density and the distance to lake, together, as the strongest predictors for squirrel midden distribution whereas open landscape and disturbed areas are avoided. It is concluded that squirrels select for high and dense forests for middens avoiding humans. This study is able to present a machine learning template to easily and rapidly produce an accurate abundance prediction which can be used for management implications. 
$1 \quad 25-04-2021$

2 Richard Robold

3 Rendsburger Landstraße 29

424113 Kiel, Germany

$5+4915779279225$

6 E-Mail contact: rr@robold.info

7 E-Mail contact author 2: fhuettmann@alaska.edu

8

9 RH: Robold et al. • High-resolution Spatial Prediction of Red Squirrel Distribution

11 High-Resolution Prediction of American Red Squirrel in Interior Alaska: A role model for 12 conservation using open access data, machine learning, GIS and LIDAR

13

14 Richard B. Robold, Institute of Arctic Biology, University of Alaska - Fairbanks, Fairbanks, 15 Alaska, United States

16 Falk Huettmann, -Institute of Arctic Biology, University of Alaska - Fairbanks, Fairbanks, 17 Alaska, United States 


\section{ABSTRACT}

19 American red squirrels (Tamiasciurus hudsonicus) are small mammals that are abundantly

20 distributed throughout the North American continent. Urbanization in the Anthropocene is now a

21 global process, and squirrels live in such landscapes. This leads to squirrels adjusting to human

22 developments. Not much is known about the distribution of squirrels and squirrel middens near

23 humans, especially not in the subarctic and sub-urbanized regions. Although this species is

24 hunted, there are no real publicly available distribution and abundance estimates nor

25 management plans and bag limits for squirrels in Alaska or in the United States known by us,

26 except the endangered Mt. Graham squirrel. In general, insufficient squirrel conservation

27 research is carried out; they are underrepresented in research and its literature. To further the

28 science-based management for such species this study aims to generate a first and digital open

access workflow as a generic research template for small mammal work including latest machine

30 learning of open source and high-resolution LIDAR data in an Open Source Geographic

31 Information System (QGIS) and ArcGIS. Machine learning has proven to be less modeler biased

32 and improve accuracy of the analysis outcome so it is the preferred approach. This template is

33 designed to be rapid, simple, robust, generic and effective for being used by a global audience.

34 As a unique showcase, here a squirrel midden survey was carried out for two years (2016 and

35 2017). These squirrel middens were detected in a research area of 45,5 hectares $\left(0,455 \mathrm{~km}^{2}\right)$ in

36 downtown Fairbanks, interior boreal forest of Alaska, U.S. Transect distances were geo-

37 referenced with a GPS and adjusted to the visual conditions to count all squirrel middens within

38 the survey area. Different layers of proximity to humans and habitat characteristics were

39 assembled using aerial imagery and LIDAR data (3D data needed for an arboreal species like the

40 red squirrels) consisting of a $3 \times 3 \mathrm{~m}$ resolution. The layer data was used to train a predictive 
41 distribution model for red squirrel middens with machine learning. The model showed the

42 relative index of occurrence (RIO) in a map and identified canopy height, distance to trails,

43 canopy density and the distance to lake, together, as the strongest predictors for squirrel midden

44 distribution whereas open landscape and disturbed areas are avoided. It is concluded that

45 squirrels select for high and dense forests for middens avoiding humans. This study is able to

46 present a machine learning template to easily and rapidly produce an accurate abundance

47 prediction which can be used for management implications. 


\section{INTRODUCTION}

49

50

51

52

53

54

55

56

57

American red squirrels (Tamiasciurus hudsonicus, Taxonomic Serial Number TSN.: 180166), hereafter referred to as red squirrels, are common in Central and South Alaska, in Canada and in large parts of the United States and live in arctic or subarctic climate as well as in more temperate climate zones (Steele 1998, Hope et al. 2016). The small-scale ecological niche of red squirrels remains poorly described and quantified for subarctic climate zones even though the macro-ecological niche and the distribution of the Tamiasciurus species has been predicted by Hope et al. (2016) and the midden-site selection of red squirrels in the Yellowstone area has recently been described by Elkins et al. (2018).

Red squirrels are considered to be primarily arboreal in coniferous, deciduous and mixed forests (Steele 1998, Rubin 2012). They mostly occur in elevations up to 760m and can live in sub- and urban landscapes, if coniferous forest habitat is present (Rubin 2012). Due to the worldwide, rapid population growth of humans in the Anthropocene (Steffen et al. 2007, Bongaarts 2009), animals must cope with the fact that more and more habitats are developed, transformed and occupied by humans (McKee et al. 2004, Hoekstra et al. 2004, Hanski 2011). To be able to live within human-made and -populated areas, these animals need to have a wide phenotypic plasticity. This can be shown by the degree of habituation to all forms of human behavior and influences (Luniak, 2004). Benefitting from human structures and resources might become inevitable. Beyond natural history, such situations are therefore of wider interest to science, e.g. for mitigation of urbanization processes and impact assessments of urbanization on animal populations, and it also helps with developing science-based management solutions for wildlife conservation in urbanized landscapes (Luniak 2004, Møller 2009). For Alaska and Fairbanks, such work in the subarctic is ongoing already, see for instance Baltensperger et al. (2013) for 
71 ravens, Baltensperger et al. (2017) for marten, Mullet et al. (2017) for noise, and Jochum et al.

72 (2014) for urban wildlife conflicts and encounters.

73 Despite being ubiquitous in Alaskan forests, red squirrels received little attention from wildlife

74 managers: for example, there is neither a publicly available management plan, bag limit or

75 budget, nor a status report to be found on the website of the Alaska Department for Fish and

76 Game (Alaska Department of Fish and Game, 2021) and the density numbers the U.S.

77 Department of Agriculture displays on the internet are derived from over 20 years old

78 publications from 1969 and 1994 (Sullivan, 1995) that carry little specifics for Alaska's diverse

79 habitats. As a global phenomenon, relevant budgets and staff assigned to similar, abundant

80 species groups with a low conservation status are usually non-existent in governance systems.

81 Like many other species on earth, red squirrels share the fate of being marginalized by such a

82 governance scheme, indicated by mostly missing management plans in North America, resulting

83 into ignorance, potential decline and extinction eventually (Czech \& Krausman 2001).

84 Being able to capture a species distribution and the wildlife-habitat association quantitatively and 85 in a digital fashion presents a major way forward for descriptive and predictive work (e.g. high-

86 precision impact studies, climate change and industrial impacts). Achieving this on a high-

87 resolution scale will further provide great progress for detailed decision-making and mitigation

88 cases for instance. It also represents a powerful way to find out more about implied mechanisms

89 and processes from behavioral patterns and helps to determine the definition and components of

90 their otherwise complex ecological niche (Guisan \& Zimmermann 2000, Barry \& Elith 2006).

91 The reliability of those niche estimations often depends on the skill of the modeler, the amount

92 and quality of data, the quality of the chosen model algorithm (Breiman 2001) as well as the

93 biologist's skills in characterizing the species (Drew et al. 2011). The definition of an ecological 
94 niche itself remains somewhat diverse and has been applied in several distinct ways (Soberon \&

95 Nakamura 2009, Cushman \& Huettmann 2010). As widely done these days, in this study the

96 concept of an ecological niche as an n-dimensional hypervolume, described by Hutchinson

97 (1957), was followed (Elith et al. 2006), allowing for computational analysis platforms (Drew et

98 al. 2011, Humphries et al. 2018). Species distribution modeling and predictions are often carried

99 out all over the globe; it is even shown by Svenning et al. (2008) that they can be used to

100 investigate the past. Arguably, those tend to be macro-ecological studies like the work of Hope et

101 al. (2016).

102

103 Still, much research relies on traditional and lower performing statistical procedures like linear

104 and logistic regressions and parsimony to predict values and goodness of fit tests for validation

105 (Breiman 2001; Humphries et al. 2018). This approach may have led to several irrelevant

106 theories and questionable scientific conclusions (Breiman, 2002; see Hochachka 2007, Cushman

107 and Huettmann 2010 and Drew et al. 2011 for new approaches). The problem can be that

108 conclusions are drawn from a wrong fit and theoretical model (McArdle 1988), but not from the

109 underlying, more complex natural mechanisms captured in the data. This can eventually result in

110 dubious if not even false conclusions if the model itself is a poor emulation (Breiman 2001).

111 With machine learning, - a non-parametric method - the outcome can be based on decision trees

112 to produce highly accurate predictions using all the possible predictors (Breiman 2001). This

113 might result in an initially less interpretable and more complicated model, especially for people

114 not trained on those works (Breiman 2001). But when inferring from predictions, it greatly

115 enhances the outcome and accuracy (Elith et al. 2006, Drew et al. 2011). It is further easy to 
116 implement and strongly recommended (e.g. Cushman and Huettmann 2010, Drew et al. 2012,

117 Humphries et al. 2018), which is why it was chosen for in this study.

119 To address the complex niche concepts, this study followed a rapid assessment concept as

120 employed by Baltensperger \& Huettmann (2015) and Kandel et al. (2015) to investigate,

121 determine and quantify factors of an ecological niche of a small mammal (rodent) in the

122 Anthropocene and to produce a predictive GIS map for inference. The main research features of

123 this study were the easily recognizable food storing and feeding location sites of red squirrels,

124 the so-called "middens" (Hatt 1929, Gurnell 1984, Steele 1998, Boon et al. 2008). For this

125 approach no multi-year fieldwork had to be conducted but robust presence field data with a

126 virtually complete detection rate were used linked with high resolution environmental data

127 layers. If successful, applying this fast template on other spatial distribution investigations would

128 save money and speed up research processes. It also presents powerful management baseline

129 data and could boost the gathering of knowledge about species niche modeling to progress

130 conservation. It can make use of latest digital opportunities like open-source code and LIDAR

131 data (light detection and ranging): a powerful system using light to produce new-dimensional

132 spatial data over land cover and height (Ohse et al. 2010 for underlying GIS model concepts).

133 LIDAR has proven to perform well in ecological modelling for squirrels, especially since it

134 allows to display habitat heterogeneity and structural features (Flaherty et al. 2014).

135 Applying these techniques would especially help squirrel conservation and management issues -

136 a species group otherwise widely overlooked and underrepresented (Koprowski \& Nandini 2008,

137 see also table 1.4 and figure 1.5 in Thorington et al., 2012) but representing the base of the food

138 chain and presenting a major micro-predator shaping the ecological community (Feldhamer et al. 
139 2003). Beyond being 'cute', small and abundant mammals are not really in the focus of the

140 public for all their habitat and conservation needs. Red squirrels virtually lack a (conservation-)

141 management program in Alaska (Alaska Department of Fish and Game, 2021) and in most parts

142 of North America, as well as any abundance, population, distribution or trend estimates (Aycrigg

143 et al. 2015); the USDA still uses density numbers which are over 20 years old (Sullivan, 1995).

144 The aim of this study is to develop a rapid niche assessment template, as earlier described, for

145 red squirrels which is cost and time effective, open access and easy to apply to improve red

146 squirrel management. Further, this investigative study was conducted to predict and then infer

147 red squirrel midden distribution in a digital fashion with machine learning for the first time. This

148 fills the earlier described knowledge gap of squirrel density and habitat use in the urbanized

149 subarctic. Thereby, it helps quantifying a squirrels' ecological niche explicit in time and space as

150 well as providing pixel-based abundance estimates using modern computational methods. This

151 allows for progress in the science-based conservation management for such species and their

152 habitat and aid the conservation of species. 


\section{STUDY AREA}

155 Considering that tree-living squirrels in the urbanized subarctic are virtually unstudied on a small

156 landscape-scale, and certainly not in the subarctic of Alaska anywhere or in the related peer-

157 reviewed literature (e.g. Boon et al. 2008, Chen and Koprowski 2016, Elkins et al. 2018, Kelly

158 and Hodges 2020), the research area was chosen as a start and to match earlier midden cruising

159 surveys from previous years (see Data collection). The earlier surveys were an exploratory 'dry

160 run' and helped to improve fieldwork and to identify middens to secure squirrel occurrences;

161 those were carried out by Ryan Adams in 2016. The research area is located North-West of

162 Fairbanks and belongs to the University of Alaska, Fairbanks (UAF) campus (see fig. 1).

163 Students, staff, public sports and recreation are now dominating this study area, making it

164 representative for a subarctic urbanized Anthropocene. In the West, the study area is demarked

165 by a highway and by the university's parking lot in the east, as well as by Smith Lake in the

166 North and the Botanical garden property in the South. The area includes an ancient boreal forest

167 surface of about $45.5 \mathrm{ha}(0.455 \mathrm{~km} 2)$; the axis of the study was approximately $880 \mathrm{~m}$ in the $\mathrm{x}$ - and

$168850 \mathrm{~m}$ in y-direction. This area is located on a ridge, and has an average elevation of $145-190 \mathrm{~m}$

169 above sea level. The center coordinates of the study area are: 459123.9 Easting and 7193150.6

170 Northing (geographic projection datum UTM NAD 83 Zone N6). The prevalent tree species are

171 white spruce (Picea glauca), black spruce (Picea mariana) and paper birch (Betula papyrifera).

172 The forest stand is part of the so-called 'potato field' and the region was used a century ago by

173 the Tanana Chiefs has a blessed gathering site for indigenous use and celebration (nowadays

174 referred to as 'Troda Yoda').

175 Furthermore, the study area has by now a well-developed, maintained and well-used trail system

176 with electric-powered lights, gravel-rock walking trails and ski grooming. It is highly used year- 
177 round for hiking, snowshoeing, olympic and recreational skiing, frisbee-golfing, dog walking

178 and several ecological surveys and studies. Some of the ski and walking trails have electric light

179 for $24 \mathrm{~h}$. These structures result into year-round frequent human presence in the campus forest.

180 The research area contains of different distinct habitats such as black and white spruce forests,

181 mixed spruce forests, general mixed forests, deciduous forests and some open grass areas and

182 wetlands. The age and density of plants differs widely in that area as well as the canopy height,

183 but the forest is 'mature' and has many old-growth trees ( $>100$ years old). The area further

184 contains high human influence, good accessibility and a vital but virtually unstudied squirrel

185 population within. Other than this study, a proper and available GIS and Remote Sensing

186 mapping is absent. Overall, we find it to be a rather good representation of urbanized landscapes

187 in interior Alaska (see also Baltensperger et al. 2013). 


\section{METHODS}

\section{Study animal and midden sites}

190 The American red squirrel (hereafter referred to as red squirrel) is a mammal, belonging to the

191 order of Rodentia (rodents) and the family Sciuridae (squirrels). Information about its taxonomic

192 status and biology can be found, among others, in the following references Kramm et al. (1975),

193 Steele (1998), Feldhamer et al. (2003), Rubin (2012), Thorington et al. (2012) and Hope et al.

194 (2016).

195 Red squirrels store food (mostly cones of white and black spruce $P$. glauca and $P$. mariana) in

196 caches, named middens, feeding frequently at these food storages (Smith M. C. 1968, Gurnell

197 1984). At these middens, cone debris accumulates and forms well-recognized piles (Gurnell

198 1984). These middens are often used for many years for feeding, and consequently these debris

199 accumulations can grow into large and persistent piles, often many decades old (Gurnell 1984).

200 The actual meaning of those middens, how these places exactly look like and how they are

201 precisely counted is not clearly defined in the literature with mutual agreement. But Gurnell

202 (1984) lists two types of midden classification: (I) clearly defined ones that consist of one huge

203 pile and a food cache (see fig. 2) and (II) diffused middens, which consist of several spread piles

204 with different caching structures (see fig. 3). Most researchers assume that each squirrel territory

205 contains one central, primary midden (Gurnell 1984, Boon et al. 2004, Reale, \& Boutin 2008)

206 and may occasionally contain several secondary middens at low population densities (Boon et al.

207 2008). Usually, bases of old (>100 years) black or white spruce trees or logs build the supporting

208 structure of middens (Smith M. C. 1968, Gurnell 1984). An earlier study of M.C. Smith (1986)

209 in Interior Alaska reported two densities: one with one squirrel per $1.6 \mathrm{ha}\left(0.016 \mathrm{~km}^{2}\right)$ assuming

210 one primary midden per squirrel and one with one squirrel per 1.2 ha $\left(0.012 \mathrm{~km}^{2}\right)($ Smith M. C. 
211 1968) considering inactive and abandoned middens, resulting in a midden density of 83 middens 212 per $\mathrm{km}^{2}$.

\section{The ecological niche of red squirrels in this study}

214 The concept of an ecological niche offers a powerful quantitative approach (Cushman and

215 Huettmann 2010, Drew et al. 2011) and is used following the definition of Hutchinson (1957) as

216 n-dimensional hypervolume. This was applied in this study providing a precise and quantitative

217 way to determine ecological niches (Stockwell 2006, Elith et al. 2006, Drew et al. 2012); it

218 primarily focusses on the species and less on its opportunities or community it lives in (Schoener

219 2009). In this study, the dimensions of the ecological niche are represented by the spatial

220 predictors (see High resolution predictors, p. 14). 


\section{Data Collection}

222 In 2016, a first exploratory survey was conducted by Ryan Adams identifying 28 midden sites

223 within the research area (see fig. 4). No specific protocol was followed for this opportunistic

224 survey, and the aim was simply to maximize detections. This data is used for validating the

225 predictions.

226 In a more detailed reference survey in 2017, the whole area was surveyed to get an absolute

227 midden count; no middens were missed. To achieve up to $100 \%$ survey coverage, the area was

228 scanned by foot using transects of varying length, orientation and distance from each other.

229 Transects were placed accordingly to weather conditions, forest and understory type which

230 limited the visibility (see fig. 5).

231 Since literature lacks a clear definition of red squirrel middens, only middens were counted with

232 a cone debris pile diameter $>20 \mathrm{~cm}$, a fresh debris height $>1 \mathrm{~cm}$ and at least one ground hole

233 (=access to food cache) within $15 \mathrm{~cm}$. Figure 3 shows a typical midden site within the study area.

234 If multiple middens occurred close to each other $(<10 \mathrm{~m})$, all counted as one diffuse midden (no

235 track was kept regarding the style and size of the midden). If two spatially close middens did not

236 belong to each other, they were counted as two. This was determined by the definition of midden

237 boundaries, size, spread of the cone debris and connecting tracks. Midden locations were

238 collected in the field using a GPS-device (Accuracy of $+/-5 \mathrm{~m}$ or better) and imported into

239 ArcGIS 10.4 by ESRI. 


\section{Data analysis and treatment}

242 For data processing and management, Ohse et al. (2009) and Zuckerberg et al (2012) was

243 followed as shown in the flowchart (see Fig. 6); Open Source QGIS and ArcGIS were used for

244 geospatial processing.

245 Training data

246 To train the model we used the 'complete study area' midden dataset from 2017. These points

247 were used as presence points of squirrel middens. Additionally, 600 random points were created

248 with the "Create Random points" tool (ArcGIS) to obtain representative pseudo-absence data

249 points. Because all middens in the research area were detected, the absence points actually

250 represent real absence data. The number of absence points was chosen to ensure a sufficient

251 density of background sampling points of 17.6 sampling points per hectare. Presence and

252 absence points were weighted in a way that resolved in an equal ratio of presences and absences

253 as suggested by Barbet-Massin et al. (2012); see Salford Predictive Modeler (SPM) also.

\section{High resolution predictors}

255 Following the concepts of Ohse et al. (2009), Herrick et al. (2013) and Baltensperger and

256 Huettmann (2015), a machine learning-based factor analysis using decision trees was applied on

257 the best-available environmental predictors. First time for red squirrels in Alaska, a high-

258 resolution approach $(3 \times 3 \mathrm{~m})$ was used with landscape predictors derived from publicly available

259 geospatial data available with FGDC (Federal Geographic Data Committee) ISO-compliant

260 metadata (in the appendix) (Alaska Division of Geological and Geophysical Surveys, 2010). It is

261 assumed that this is an appropriate biological scale for squirrels providing new insights.

262 Matching the precision and accuracy of the GPS-device, the satellite images and the LIDAR 
263 resolution, the GIS-layers were produced on that $3 \times 3 \mathrm{~m}$ resolution. Every layer is projected in a

264 UTM NAD 1983 N6 projection with coordinates in meters. In this study, experience is provided

265 how this data workflow makes this approach usable as a generic template for further density and

266 abundance estimations on a small scale and predictions of small animals' presence/absence in a

267 human-driven environment.

268 The set of predictors used consisted of the following groups:

269 Euclidean distance

270 To identify specific areas of human disturbance and natural landscape division, polygons of

271 important landscape features were digitized with the help of optical imagery from ESRI's World

272 Imagery service (ESRI, 2011), which is a combination of satellite and aerial imagery (pixel size

273 up to $30 \mathrm{~cm} \times 30 \mathrm{~cm}$ ). Polygons showing the outline of different structures were hand traced

274 (ArcGIS). The tool "Euclidean Distance" was then used to produce a proximity (Euclidean

275 distance) layer to each of these following geographic features: the lake, the walking trail for dogs

276 in the wintertime, the ski- and snowshoe trails, the highway and buildings (maps are found in the

277 appendix). These predictors were chosen because they represent human activities and report

278 disturbance impacts for squirrels in the research area. Proximities allow to assess spatial

279 dependencies, interactions and relationships effectively (see for instance Huettmann and

280 Diamond 2001 and Kandel et al. 2015 for applications).

281 LIDAR and Satellite images

282 While optical imagery allows for a basic survey of the landscape, further information is needed

283 to describe its three-dimensional form for squirrel distribution. The structure of the canopy

284 height in particular is an essential metric for arboreal species like the red squirrel (Kemp \& 
285 Keith, 1970) which can superiorly be described using LIDAR data (St. Onge \& Achaichia, 286 2001). It provides an aerial 3D-scan of an area using laser pulses. Although there are several

287 remote sensing techniques that try to describe vertical vegetation structure, an airborne LIDAR

288 dataset collected by the Alaska Department of Geological and Geophysical Surveys (DGGS)

289 provided the best available and highest spatial resolution as well as ease-of-use for the area of 290 interest.

291 DGGS provides a 'point cloud' (a set of data points in three-dimensional space) of LIDAR

292 returns with each point classified by the height ('ground' or 'non-ground') and type of the return;

293 point spacing was 2.7 feet. The vertical accuracy of the dataset was 0.251 feet (95\% confidence

294 interval) (Alaska Division of Geological and Geophysical Surveys, 2010). Provider-classified

295 data often leaves a significant portion of vegetated points unclassified, so the unclassified and

296 classified 'vegetation' points were combined to represent all vegetation. Using the final combined

297 class, two simple structure metrics were derived. First, canopy density was described by

298 calculating the percentage of vegetated returns in a $3 \times 3 \mathrm{~m}$ square. Second, tree height was

299 calculated by finding the height of the highest vegetated return in the same grid. Isolating the

300 ground points allowed to further describe a few significant terrain variables: aspect, slope and 301 elevation.

302 To sum up the used predictors:

303 - $\quad$ Euclidean distance to the lake

304 - Euclidean distance to the walking trail for dogs in the wintertime

305 - $\quad$ Euclidean distance to the ski- and snowshoe trails

306 - $\quad$ Euclidean distance to the highway and to the buildings 
307 - Canopy height

308 - Canopy density

309 - Slope

$310-\quad$ Aspect

311 - Elevation.

\section{GIS Data extraction}

313 All layers were overlaid with the presence and absence points. Data was extracted from the

314 attribute table using the "Extract Multi-values to points" tool (ArcGIS). The resulting table is the

315 underlying data cube used for the machine learning-based distribution model and subsequent GIS

316 modeling.

\section{Predictive modeling with machine learning}

318 A predictive distribution model was created using the TreeNet machine learning algorithm in the

319 SalfordPredictiveModeler (SPM 8.0) from Salford Systems Ltd, which provides possibilities to

320 control the models' parameters. The default setting was chosen as it provides the best-known

321 generic solutions (400 trees, terminal branch samples per node $=2$, node depth $=10)($ Chunron et

322 al. 2017; see subsequent citations for their performance). As shown by Craig and Huettmann

323 (2009) and others (Ohse et al. 2009, Humphries 2010, Drew et al. 2011, Humphries et al. 2018),

324 the algorithm is common and reliable for building ecological models. These algorithms are

325 known to be robust and accurate for regression as well as classification (Fernandez-Delgado et

326 al. 2014). The algorithm was trained to create a density model for squirrel middens as well as a 
327 RIO (relative index of occurrence) of middens to show the most suitable habitats for squirrels,

328 their predicted hotspots and abundances.

329 To obtain spatial prediction surfaces, an equally spaced point lattice grid was created within the 330 research area, using the "Regular Point" tool (QGIS). Data from the different predictor layers

331 were extracted (ArcGIS). This lattice grid was 'scored' in SPM 8.0 using the model created from

332 the presence/absence points. Giving every point a value between 0 and 1 , representing how likely

333 this point is to contain a midden site $(0=$ not likely, $1=$ very likely $)$, this grid gives a prediction

334 of the relative index of occurrence (RIO) of middens. Probabilities are not used here because

335 required parametric assumptions are not met with complex predictors and because machine

336 learning is using a different concept (trees and splitting rules; Breiman 2001). With the "Inverse

337 Distance Weighting (IDW)" tool (ArcGIS), an interpolation raster was generated to get a

338 smoothed-out prediction covering the entire research area, showing the RIO of a squirrel midden

339 in a $3 \times 3 \mathrm{~m}$ resolution.

340 The accuracy of the model is determined by the area under the curve (AUC) of the Relative

341 Operating Characteristic (ROC), as described by Pierce and Ferrier (2000)

343 Validation of the model prediction

344 To validate the results, the independent data of 2016 was used. Due to its smaller extent, it is of

345 high quality for presence and absence. The RIO for these field points was extracted to assess

346 how the predictions matched the independent field data. That way it is possible to get an

347 unbiased quantitative assessment how good the model works in the real world. 


\section{RESULTS}

349 The machine learning approach of Breiman (2001) was followed inferring from predictions; the

350 prediction surfaces are regarded as the most important outcome. The internal ROC showed an

351 accuracy greater than $83 \%$ of the of the midden prediction, which means this model performs

352 better than a moderate accuracy. Also, data is available open access for further assessment and 353 use.

354 A total number of 198 middens were found within the research area following the explained 355 methods. This midden estimate assumes $100 \%$ detectability from the surveys for the study area 356 (45 ha; $\left.0.45 \mathrm{~km}^{2}\right)$. This results in a density of 4.35 squirrel midden per ha $\left(435\right.$ per $\left.\mathrm{km}^{2}\right)$. The RIO 357 also allows for a binary classification of the area: occupied or not occupied by squirrels. To 358 determine the threshold for the area occupied, a one-sided confidence interval of $95 \%$ of the

359 values is used, resulting in a RIO cut-off value of $\mathrm{t}_{\text {occupied }} \geq 0.205$ (see fig.7). The resulting

360 subsequent midden density for this further so-called "occupied area" is 6.3 squirrel midden per

361 ha, and the total area occupied by squirrels amounts to 29.85 ha with 188 predicted middens.

362 Analyzing the distribution of the midden points and their relation to the chosen predictors, a

363 predictive model showing the relative index of occurrence (RIO) was generated (see fig. 8).

364 In figure 8, the highest RIO is shown in red, indicating a fragmented RIO of squirrels in the 365 study area suggesting clusters and patches - a population structure and likely territories - for

366 squirrels in the study area. High RIO areas are located along the Northern boundary on the right

367 side of the study area where the trees are relatively high and the distance to the highway is great.

368 In addition, the areas in the very North of the research area show high numbers of red patches

369 (close to the lake and very dense canopy) as well as in the South of the research area (old-growth 
370 forest with not too many trails). The parts between the dark green patch (a meadow) and the

371 center of the research area (old-growth forest with high trees) also show a relatively high-

372 predicted midden density which means a high possibility for midden occurrence in comparison

373 to the rest of the area. The area very close to the highway on the West does not show a high RIO

374 as well as the middle of the lower half of the research area which might be due to a dense

375 understory and low trees as well as due to the high disturbance.

376 The map (see figure 8) shows that the squirrels' midden sites mostly avoid trails (green to dark

377 green lines throughout the research area) which is clearly a highly human influenced structure. It

378 was also found that they strictly avoid treeless areas (dark green area in the Northeast) and tend

379 to avoid the highway area (another human influence) as well as areas with high canopy density

380 and low canopy height.

381

382 Predictor importance

383 Following the approach of Breiman (2001), the predictions are the most important outcome for 384 us.

385 The different predictors were scored regarding their importance for the prediction of midden

386 occurrence. In a singular view, canopy height is according to the SPM ranking metric the most

387 important predictor for our midden distribution (see Table 1), supporting squirrels need big trees.

388 Distance to trails, canopy density and the distance to the lake are the next important factors, all

389 of them scoring an importance rank of approximately $70 \%$. The next three predictors, Aspect, the

390 distance to the highway and the distance to buildings come after a gap and score in between 50 
391 and $60 \%$. The three least important factors for squirrel midden distribution seem to be the

392 distance to the dog trail, the elevation and the slope of the ground, all scoring under $50 \%$.

393 It should be kept in mind that squirrels got predicted here as a multivariate package, synergies

394 matter here, not individual predictors, and those consist at least of an interaction between canopy

395 height, distance to trails, canopy density and distance to lake.

396 Partial dependence plots

397 The partial dependence plots show the direction of the RIO relationship for each predictor with

398 all else kept constant. It represents the major signals in the data. The American red squirrel

399 prefers tall trees over small ones; the plot shows that a canopy height over ca. 9m affect the RIO

400 in a positive way. The higher the trees are the more likely is a squirrel to build a midden in that

401 pixel (see fig. 9).

402 The trail system also affects whether and where squirrels are constructing a midden. A distance

403 greater than $10 \mathrm{~m}$ enlarges the RIO - it makes a pixel more likely to contain squirrel middens the

404 further it is away from trails (see fig. 10).

405 Further, the actual density of the canopy also effects the RIO. A low canopy density reduces the 406 possibility of a midden, and the higher the canopy density gets, the more likely a pixel is to 407 contain squirrel middens (see fig. 11).

408 The last strong predictor affecting the RIO is the distance from the lake. The closer to the lake, 409 the higher is the possibility of a squirrel starting a midden. Further away than ca. $250 \mathrm{~m}$ from 410 such wet areas, the RIO is influenced in a negative way (see fig. 12). 
411 Taken all together, squirrels prefer high trees, greater distance from disturbance (such as

412 humans), show a preference for dense canopy and wet land. They seem to avoid areas that have

413 the following characteristics: small trees and/or open with a lot of disturbance.

414 Once more it should be kept in mind that these predictors are all acting in concert and that a

415 reductionist/parsimonious view just interpreting partial dependence plots individually and

416 selectively is not recommended (Breiman 2001, Humphries et al. 2018). For a true ecological

417 understanding of squirrels a the multivariate perspective is needed instead and showing overall

418 that human impacts are the biggest predictors for squirrels overall, by avoiding human impacts

419 and living next to them but in a safe distance.

\section{Model Validation}

422 Opposite to frequency statistic and probabilities (Guisan \& Zimmerman, 2000) in machine

423 learning work, and when based on CARTs, the RIO is not necessarily symmetric nor carries a

4240.5 cut-off. The RIO-values to the midden points from the validation survey in 2016 are

425 relatively high. They all are greater than 0.22 , the mean is 0.3523 and the highest is 0.4996 . Half

426 of the values lie between 0.2948 and 0.4366 . For comparison, the highest overall predicted value

427 is 0.6425 . Those high prediction values of the previous year show that the model is able to assign

428 high values to areas that actually contain middens and therefore performs well. Ninety-three

429 percent of all validation values are above the average prediction score of the prediction grid

430 points, thus the model performs significantly higher than a random guess. The midden scores of

431 the 2016 survey score definitely similar to the midden locations of 2017 survey with some

432 outliers at the lower tail which are either mis-classified middens from the survey in 2016 or 
433 middens which were abandoned in 2017. Likely it reflects midden dynamics. It offers an 434 interesting study to work on rgarding midden turn-over time ('blinking') and the role of 435 individual outlier middens). 


\section{DISCUSSION}

437 This is the first high resolution $(3 \times 3 \mathrm{~m})$ predictive midden distribution model of red squirrels in

438 Alaska, in the circumpolar subarctic, in North America and in the world. Similar studies have

439 been done by Elkins et al. (2018), modelling the habitat of red squirrels with a generalized linear

440 mixed model and by Pereira and Itami (1991), who modeled the habitat of the Mt. Graham

441 Squirrel (Tamiasciurus hudsonicus grahamensis) using logistic multiple regression.

442 Nevertheless, they differ in the use of LIDAR, machine learning and the human disturbance

443 variables and are therefore not fully comparable. This study still agrees with mostly all findings

444 of those mentioned but can further predict the occurrence of squirrel middens accurately on a

445 small scale in an urbanized habitat in the subarctic, which was previously unknown. Flaherty et

446 al. (2014) used LIDAR data for modelling the habitat of the European red squirrel (Sciurus

447 vulgaris) with similar outcomes and found that LIDAR-derived explanatory variables perform

448 well for habitat modelling, which leads to the conclusion that LIDAR is a powerful remote

449 sensing tool and should not be overlooked.

450 This study provides thus the first predictive model for squirrel middens on a small scale (extent

451 of $800 \mathrm{~m}$, and $3 \times 3 \mathrm{~m}$ resolution) in an urbanized area and in the subarctic using open access data

452 and machine learning. Beyond squirrels, it is assumed that this model concept can break some

453 new ground for conservation worldwide. The model gives new quantified insight explicit in time

454 and space on the ecological niche of the red squirrel and its habitat; it allows for transparent and

455 repeatable science as well as for the first quantitative estimations about predictors of squirrel

456 midden distribution using open access data. Red squirrels prefer high canopy trees to build their

457 middens (Fig. 9), which agrees with what the literature elaborates about squirrel habitat choice

458 for the red squirrel (Kemp \& Keith, 1970) as well for the European red squirrel (Rima et al. 
459 2010, Flaherty et al. 2014). The fact, that squirrels give preference to dense (Gurnell, 1984) or

460 interlocking canopy to increase their foraging success and their escape possibilities from

461 predators ( Elkins et al. 2018, Steele 1998, Vahle \& Patton 1983, Smith 1968) supports these

462 outcomes.

463 Because squirrels avoid disturbed areas and predators in a similar way (Gill et al. 1996,

464 Sutherland, \& Watkinson 1996) it was expected that red squirrels also avoid human disturbance,

465 represented through the trails (see Fig. 1). Squirrels will not build their middens right on the trail

466 (because of humans walking right through and the lack of trees), but it is noteworthy that they try

467 to avoid the trails until a certain 'safety' distance; the further away from the trail, the higher is

468 the RIO for a midden (see Fig. 10). It is also noticeable that the RIO of a midden increases with

469 the proximity to the lake.

470 According to Gurnell (1984), a squirrel has approximately one midden within its territory.

471 Considering the 198 middens counted in the research area (45.5ha; $\left.0.455 \mathrm{~km}^{2}\right)$, the squirrels'

472 territories would have an average size of $0.23 \mathrm{ha}\left(0.15\right.$ for the estimated occupied area) $\left(2300 \mathrm{~m}^{2}\right)$

473 which is in line with reported average sizes of a squirrel's territory of 0.24-0.98 ha (2400 - 9800

$\left.474 \mathrm{~km}^{2}\right)($ Hatt 1929, Steele 1998). In contrast, Smith (1968) reports bigger territories in Interior

475 Alaska, exceeding from $1.2 \mathrm{ha}$ up to $4.8 \mathrm{ha}\left(12000-48000 \mathrm{~m}^{2}\right)$. It is currently unclear how

476 middens and squirrel territories are related. Steele (1998) reports that squirrels have one or a few

477 central middens, so does Boon et al. (2008) who mentions one central and several secondary

478 middens, which may occur at low population densities. Therefore, it is very difficult to estimate a

479 population density based on the number of middens per se. For further research, it is

480 recommended to score midden characteristics to find relationships between certain midden

481 features, squirrel abundance and behavior. To prevent future flaws in scientific research and 
482 subsequently improve management, the use and meaning of "midden" as a definite science term

483 and concept needs to be refined and finally unified.

484 In this study, territory sizes ranged between 0.23 ha (one midden per squirrel) and $0.92 \mathrm{ha}$ (one 485 primary and up to three secondary middens), resulting in an estimation of 49 and 198 squirrels 486 within the study area respectively. If only the predicted occupied area is used (which contains $48795 \%$ of the middens), the estimate lies between $47-188$ squirrels in this area. Densities are 1.08 $488-4.35$ squirrels per ha $\left(108-435\right.$ squirrels per $\left.\mathrm{km}^{2}\right)$ for the research area and $1.57-6.29$ 489 squirrels per ha (157- 629 squirrels per $\left.\mathrm{km}^{2}\right)$ in the predicted occupied area respectively, which is 490 similar to a found squirrel density of 1.83 squirrels per ha (183 per $\left.\mathrm{km}^{2}\right)$ in Interior Alaska by

491 C.H. Brink (1964). On the other hand, compared with a reported density of $0.2-0.6$ squirrels per 492 ha $\left(20-60\right.$ per $\left.\mathrm{km}^{2}\right)$ by M.C. Smith (1968) it seems high; nevertheless, these results were found 493 after one and two years of crop failure in white spruce. There are no current density numbers of 494 red squirrels in Alaska, but research at Kluane Lake by Villette et al. (2017) reports a squirrel 495 density of $2.19-4.99$ squirrels per ha $\left(219-499\right.$ squirrels $\left./ \mathrm{km}^{2}\right)$ which is similar to the findings 496 in this study. Therefore, the found results seem to be accurate.

497 Regarding future research, it would be relevant for an effective conservation management to 498 carry out the same study on a larger scale ("scaling up" e.g. Tanana Forest in interior Alaska) to 499 see a change with increasing distance from human structures and disturbance. It is expected that 500 the squirrel density is increasing with increasing distance to human disturbance but 501 simultaneously slightly decreasing through predation pressure in greater distances. That is 502 because predators seem to keep greater spacing in between themselves and humans and might 503 limit the squirrel density much further away from human disturbance. This phenomenon of 504 indirect effects of humans on predator-prey interactions was described by Muhly et al. (2011) for 
505 large mammalian wildlife species and it would be of interest if the same is applicable for small

506 mammals like squirrels.

507

508 Although squirrels are hunted in Alaska, there is a knowledge gap regarding abundance,

509 distribution, population trends, viable harvest rates and sensitivities. Currently a laissez-faire

510 approach is employed for abundant small mammal groups such as red squirrels in the US

511 (Steiner \& Huettmann, 2021), indicated by the missing management plans on the website of the

512 Department for Fish and Wildlife in many states. Similar applies worldwide, especially in the

513 tropics where many squirrel species occur but are nearly unstudied (Koprowski \& Nandini,

514 2008). In the year 2021 this should be dramatically improved towards good and defendable

515 professional and ecological research standards, e.g. as stated in Silvy (2012) for good wildlife

516 management concepts and best professional practice. Game species are to be managed with

517 science-based models and research data.

518

519 MANAGEMENT IMPLICATIONS

520 In the spirit of rapid assessment and its global applicability (Ohse et al. 2010 and Kandel et al.

5212015 for an example), the design of this study was kept as simple and cheap as possible to

522 guarantee an easy reproducibility and transferability of this workflow for future applications.

523 Achieving the aim of this study, a first template of how to use machine learning to produce

524 accurate small-scale predictions for conservation and ecological management is provided. Using

525 the same workflow, this can easily be transferred to other animals which regularly use permanent

526 structures like beavers (Graf et al., 2016), prairie dogs and burrowing owls (Alverson \& 
527 Dinsmore, 2014). Modelling the abundance of red squirrel middens proved how specific driving

528 factors like canopy height and the distance to trails determine squirrel distribution in their

529 realized niche. Those important factors should subsequently be targeted in real-world

530 management to deal with the rapid alterations of ecological niches due to climate change and

531 anthropogenic development. This is especially important for the subarctic, where temperature

532 will increase by about $4-9{ }^{\circ} \mathrm{C}$ by year 2100 (IPCC, 2013), which will bring significant changes

533 in ecosystem dynamics (Peñuelas \& Filella 2001).

\section{ACKNOWLEDGEMENTS}

535 We especially thank Aidan Myers for preparing all the LIDAR data and Ryan Adams for the

536 control collection in 2016. We acknowledge the University of Fairbanks, Salford Systems Ltd

537 for their software use, IAB and the EWHALE lab and its students. This is the EWHALE lab

538 publication \#188. We also thank the Van Hall Larenstein University of Applied science in

539 Leeuwarden, Netherlands and especially Mr. van Wijk. Also, thanks go out to the International

540 Office of the UAF and a personal thanks to Mr. Jan Geisler. 


\section{CITED LITERATURE}

542 Alaska Department of Fish and Game. (2021, April 20). Alaska Department for Fish and Game:

543 Species: Animals: Red Squirrel. Retrieved from Alaska Department of Fish and Game - Website:

544 http://www.adfg.alaska.gov/index.cfm?adfg=redsquirrel.main

545 Alaska Division of Geological and Geophysical Surveys. (2010, April 25). Alaska Division of

546 Geological and Geophysical Surveys. Retrieved from Alaska Division of Geological and

547 Geophysical Surveys: Elevation Portal: https:/elevation.alaska.gov/\#64.86187:-147.85499:15

548 Kristen M. Alverson, Stephen J. Dinsmore, Factors affecting Burrowing Owl occupancy of

549 prairie dog colonies, The Condor, Volume 116, Issue 2, 30 April 2014, Pages 242-250,

550 https://doi.org/10.1650/CONDOR-13-167.1

551 Aycrigg, J., G. Beauvais, T. Gotthardt, F. Huettmann, S.Pyare, M.Andersen, D.Keinath,

552 J.Lonneker, M.Spathelf, and K.Walton (2015) Novel Approaches to Modeling and Mapping

553 Terrestrial Vertebrate Occurrence in the Northwest and Alaska: An Evaluation. Northwest

554 Science 89(4):355-381. doi: /dx.doi.org/10.3955/046.089.0405

555 Baltensperger, A. P., \& Huettmann, F. (2015). Predictive spatial niche and biodiversity hotspot 556 models for small mammal communities in Alaska: applying machine-learning to conservation 557 planning. Landscape Ecology, 681-697.

558 Baltensperger, A. P., Mullet, T. C., Schmid, M. S., Humphries, G., Köver, L., \& Huettmann, F.

559 (2013). Seasonal observations and machine-learning-based spatial model predictions for the

560 common raven (Corvus corax) in the urban, sub-arctic environment of Fairbanks, Alaska. Polar

561 Biology, 1587-1599. 
562 Barbet-Massin, M., Jiguet, F., Albert, C.H. and Thuiller, W. (2012), Selecting pseudo-absences

563 for species distribution models: how, where and how many?. Methods in Ecology and Evolution,

564 3: 327-338. https://doi.org/10.1111/j.2041-210X.2011.00172.x

565 Barry, S., \& Elith, J. (2006). Error and uncertainty in habitat models. Journal of Applied

566 Ecology, 413-423.

567 Bongaarts, J. (2009). Human population growth and the. Philosophical Transactions of the Royal 568 Society, 2985-2990.

569 Boon, A. K., Reale, D., \& Boutin, S. (2008). Personality, habitat use, and their consequences for 570 survival in North American red squirrels Tamiasciurus hudsonicus. Oikos(117), 1321-1328.

571 Breiman, L. (2001). Statistical Modeling: The two cultures. Statistical Science, 199-215.

572 Brink, C.H. (1964). Spruce seeds as food of the squirrels Tamiasciurus hudsonicus and

573 Glaucomys sabrinus in Interior Alaska. University of Alaska. http://hdl.handle.net/11122/8198

574 Chen HL, Koprowski JL (2016) Differential Effects of Roads and Traffic on Space Use and 575 Movements of Native Forest-Dependent and Introduced Edge-Tolerant Species. PLoS ONE 576 11(1): e0148121. https://doi.org/10.1371/journal.pone.0148121

577 Chunrong M.,F. Huettmann,Yu. Guo, Xu.Han, and L. Wen (2017) Why choose Random Forest 578 to predict rare species distribution with few samples in large undersampled areas? Three Asian 579 crane species models provide supporting evidence. Peerj, doi:10.7717/peerj.2849

580 Craig, E., \& Huettmann, F. (2009). Using "Blackbox" Algorithms Such as TreeNET and

581 Random Forests for Data-Ming and for Finding Meaningful Patterns, Relationships and Outliers 
582 in Complex Ecological Data. Developing New Methodologies Through Pattern Discovery and

583 Recovery Intelligent Data Analysis, 65-84.

584 Cushman, S. A., \& Huettmann, F. (2010). Introduction: Ecological Knowledge, Theory and 585 Information in Space and Time. tokyo: Springer.

586 Czech, B., \& Krausmann, P. R. (2001). The endangered species act. Baltimore: The John 587 Hopkins University Press.

588 Drew, C. A., Wiersma, Y. F., \& Huettmann, F. (2011). Predictive Species and Habitat Modeling 589 in Landscape Ecology - Concepts and Applications. New York, Dordrecht, Heidelberg, London: 590 Springer.

591 Elith*, J. , H. Graham*, C. , P. Anderson, R. , Dudík, M. , Ferrier, S. , Guisan, A. , J. Hijmans, R. 592 , Huettmann, F. , R. Leathwick, J. , Lehmann, A. , Li, J., G. Lohmann, L. , A. Loiselle, B. , 593 Manion, G. , Moritz, C. , Nakamura, M. , Nakazawa, Y., McC. M. Overton, J. , Townsend

594 Peterson, A., J. Phillips, S. , Richardson, K. , Scachetti-Pereira, R., E. Schapire, R., Soberón, J. 595 , Williams, S. , S. Wisz, M. and E. Zimmermann, N. (2006), Novel methods improve prediction 596 of species' distributions from occurrence data. Ecography, 29: 129-151.

597 doi: $10.1111 / \mathrm{j} .2006 .0906-7590.04596 . \mathrm{x}$

598 Elkins, Eric \& Tyers, Daniel \& Frisina, Michael \& Rossi, Joao \& Sowell, Bok. (2018). Red

599 Squirrel (Tamiasciurus hudsonicus) Midden Site Selection and Conifer Species Composition.

600 Environmental Management and Sustainable Development. 7. 15. 10.5296/emsd.v7i2.12674.

601 Esri. (2013) “World_Imagery”. http://goto.arcgisonline.com/maps/World_Imagery 
602 Feldhamer, G. A., Thompson, B. C., \& Chapman, J. (2003). Wild Mammals of North America:

603 Biology, Management, and Conservation. Baltimore: The John Hopkins University Press,

604 Baltimore, Maryland.

605 Fernandez-Delgado, M., Cernadas, E., Barro, S., \& Amorim, D. (2014). Do we Need Hundreds 606 of Classifiers to Solve Real World Classification Problems? Journal of Machine Learning 607 Research, 3133-3181.

608 Flaherty, Silvia S. \& Lurz, Peter W.W. \& and Patenaude, Genevieve "Use of LIDAR in the 609 conservation management of the endangered red squirrel (Sciurus vulgaris L.) "Journal of 610 Applied Remote Sensing, 8(1), 083592 (14 July 2014). https://dio.org/10.1117/1.JRS.8.083592

611 Graf, P.M., Mayer, M., Zedrosser, A., Hackländer, K., Rosell, F.. Territory size and age explain 612 movement patterns in the Eurasian beaver. Mamm Biol 81, 587-594 (2016).

613 https://doi.org/10.1016/j.mambio.2016.07.046

614 Gill, J. A., Sutherland, W. J., \& Watkinson, A. R. (1996). A Method to Quantify the Effects of 615 Human Disturbance on Animal Populations. Journal of Applied Ecology, 786-792.

616 Grinell, J. (1917). The Niche-Relationships of the California Thrasher. The Auk, 427-433.

617 Guisan, A., \& Zimmermann, N. E. (2000). Predictive habitat distribution models in ecology.

618 Ecological Modelling, 147-186.

619 Gurnell, J. (1984). Home range, territoriality, caching behaviour and food supply of the red 620 squirrel (Tamiasciurus hudsonicus fremonti) in a subalpine lodgepole pine forest. (A. f.

621 Behaviour, Ed.) Animal Behaviour, pp. 1119-1131. 
622 Hanski, I. (2011). Habitat Loss, the Dynamics of Biodiversity, and a Perspective on

623 Conservation. AMBIO: A Journal of the Human Environment, 248-255.

624 Hatt, R. T. (1929). The red squirrel: its life history and habits, with special reference to the 625 Adirondacks of New York and the Harvard Forest. Roosevelt Wild Life Forest Experiment 626 Station, 1-4.

627 Herrick, K. A., Huettmann, F., \& Lindgren, M. A. (2013). A global model of avian influenza 628 prediction in wild birds: the importance of northern regions. Veterinary Research, 44:42.

629 Hochachka W, Caruana R, Fink D, Munson A, Riedewald M, Sorokina D, Kelling S (2007) Data 630 mining for discovery of pattern and process in ecological systems. Journal of Wildlife 631 Management 71: 2427-2437.

632 Hoekstra, J. M., Boucher, T. M., Ricketts, T. H., \& Roberts, C. (2004). Confronting a biome 633 crisis: global disparities of habitat loss and protection. Ecology Letters, 23-29.

634 Hope, Andrew G.\& Malaney, Jason L.\& Bell, Kayce C.\& Salazar-Miralles, Fernando \& Chavez, 635 Andreas S. \& Barber, Brian R. \& Cook, Joseph A., Revision of widespread red squirrels (genus: 636 Tamiasciurus) highlights the complexity of speciation within North American forests. Molecular 637 Phylogenetics and Evolution, Volume 100, 2016, Pages 170-182, ISSN 1055-7903. 638 https://doi.org/10.1016/j.ympev.2016.04.014.

639 Huettmann F., and Diamond A.W. (2001) Seabird colony locations and environmental 640 determination of seabird distribution: A spatially explicit seabird breeding model in the 641 Northwest Atlantic. Ecological Modelling 141: 261-298. 
642 Humphries, G. R. (2010). The ecological niche of storm -petrels in the north pacific and a global 643 model of dimethylsulfide concentration. Unpublished M.Sc. thesis. Fairbanks: University of 644 Alaska Fairbanks.

645 Humphries, G., D.R. Magness and F. Huettmann. (2018). Machine Learning for Ecology and 646 Sustainable Natural Resource Management. Springer, Switzerland

647 Hutchinson, G. E. (1957). Concluding remarks. Cold Spring Harbor Symposia on quantitative 648 Biology, 415-427.

649 IPCC (2013) Summary for policymakers. In: Climate Change 2013 (AR5) The Physical Science 650 Basis. Contribution of Working Group I to the Fifth Assessment Report of the Intergovernmental 651 Panel on Climate Change. Cambridge University Press, Cambridge.

652 Jochum, K. A., Kliskey, A.A., Hundertmark, K. \& Alessa, L. (2014). Integrating complexity in 653 the management of human-wildlife encounters. Global Environmental Change. 26. 73-86. 654 10.1016/j.gloenvcha.2014.03.011.

655 Kandel K., Huettmann F., Suwal, M.K., Regmi, G.R., Nijman, V., Nekaris, K.A.I., Lama, S.T., 656 Thapa, A., Sharma, H.P. \& Subedi, T.R. (2015). Rapid multi-nation distribution assessment of a 657 charismatic conservation species using open access ensemble model GIS predictions: Red panda 658 (Ailurus fulgens) in the Hindu-Kush Himalaya region. Biological Conservation, 150-161.

659 Kelly, Angelina J., Hodges Karen E., Post-fire salvage logging reduces snowshoe hare and red 660 squirrel densities in early seral stages, Forest Ecology and Management, Volume 473, 2020, 661 118272, ISSN 0378-1127, https://doi.org/10.1016/j.foreco.2020.118272. 
662 Kemp, G. A., \& Keith, L. B. (1970). Dynamics and Regulation of Red Squirrel (Tamiasciurus

663 Hudsonicus) Populations. Ecology, 763-779.

664 Koprowski, John \& Nandini, Rajamani. (2008). Global hotspots and knowledge gaps for tree and 665 flying squirrels. Current Science. 95. 851-856.

666 Kramm, K. R., Maki, D. E., \& Glime, J. M. (1975). Variation within and among Populations of 667 Red Squirrel in the Lake Superior Region. Journal of Mammalogy, 258-262.

668 Luniak, M. (2004). Synurbanization - adaption of animal wildlife to urban development.

669 Proceedings of the 4th International Symposium on urban wildlife conservation, 50-54.

670 Møller, A. P. (2009). Successful city dwellers: a comparative study of the ecological

671 characteristics of urban birds in the Western Palearctic. Oecologia, 849-858.

672 McArdle, BH. (1988). The structural relationship: regression in biology. Can. J. Zool. 66(11): $673 \quad 2329-2339$

674 McKee, J. K., Sciulli, P. W., Fooce, D., \& Waite, T. A. (2004). Forecasting global biodiversity 675 threats associated with human population growth. Biological Conservation, 161-164.

676 Mullet, T. C., Morton, J.M., Gage, S.H. \& Huettmann F. (2017). Acoustic Footprint of 677 Snowmobile Noise and Natural Quiet Refugia in an Alaskan Wilderness. Natural Areas Journal $678 \quad 37(3): 332-349$

679 Nielsen, S.E., G. B. Stenhouse, H. L. Beyer, F. Huettmann, and M. S. Boyce (2008), Can natural 680 disturbance-based forestry rescue a declining population of grizzly bears? Biological 681 Conservation 141:2193-2207. 
682 Ohse, B., Huettmann, F., \& Ickert-Bond, S. M. (2009). Modeling the distribution of white spruce 683 (Picea glauca) for Alaska with high accuracy: an open access role-model for predicting tree 684 species in last remaining wilderness areas. Polar Biology, 1717-1729.

685 Peñuelas J, Filella I (2001) Phenology: responses to a warming world. Science, 294, 793-795.

686 Pereira, J. M. C. and R. M. Itami. 1991. GIS-based habitat modeling using logistic multiple 687 regression: a study of the Mt. Graham red squirrel. Photogrammetric Engineering and Remote 688 Sensing 57:1475-1486.

689 Pierce, J., \& Ferrier, S. (2000). Evaluating the predictive performance of habitat models 690 developed using logistic regression. Ecological Modelling, 225-245.

691 Rima, P. C., Cagnin, M., Aloise, G., Preatoni, D., \& Wauters, L. A. (2010). Scale-dependent 692 environmental variables affecting red squirrel (Sciurus vulgaris meridionalis) distribution. Italian 693 Journal of Zoology, 92-101.

694 Rubin, C. (2012, June 15). Animal Diversity web: Tamiasciurus hudsonicus. Retrieved from 695 Animal Diversity web:

696 http://animaldiversity.org/accounts/Tamiasciurus_hudsonicus/\#632143B9-2D74-4F20-B500697 5B5F9FE148CE

698 Schoener, T. W. (2009). Ecological Niche. In S. A. Levin, S. R. Carpenter, H. J. Godfray, A. P. 699 Kinzig, M. Loreau, J. B. Losos, C. G. Morris, The Princeton Guide to Ecology (pp. 1-3).

700 Princeton: Princeton University Press.

701 Silvy, N. J. (2012). The wildlife techniques manual. Baltimore, Md: Johns Hopkins University 702 Press. 
703 Smith, C. C. (1968). The Adaptive Nature of Social Organization in the Genus of Three Squirrels

704 Tamiasciurus. Ecological Monographs, 31-64.

705 Smith, M. C. (1968). Red Squirrel Responses to Spruce Cone Failure in Interior Alaska. The 706 Journal of Wildlife Management, 305-317.

707 Soberon, J., \& Nakamura, M. (2009). Niches and distributional areas: Concepts, methods.

708 Proceedings of the National Academy of Sciences of the United States of America, 1964470919650.

710 Steele, M. A. (1998, June 1). Tamiasciurus hudsonicus. Mammalian Species, 586, 1-9.

711 Steffen, W., Crutzen, P. J., \& McNeill, J. R. (2007). The Anthropocene: Are Humans Now

712 Overwhelming the Great Forces of Nature. A journal of the human environment, 614-621.

713 Steiner, M. \& Huettmann, F. (2021) Justification for a taxonomic conservation

714 update of the rodent genus Tamiasciurus: addressing marginalization and mis-prioritization of

715 research efforts and conservation laissez-faire for a sustainability outlook, The European

716 Zoological Journal, 88:1, 86-116, DOI: 10.1080/24750263.2020.1857852

717 Stockwell, D. R. (2006). Improving ecological niche models by data mining large environmental

718 datasets for surrogate models. Ecological Modelling, 188-196.

719 Sullivan, Janet. 1995. Tamiasciurus hudsonicus. In: Fire Effects Information System, [Online].

720 U.S. Department of Agriculture, Forest Service, Rocky Mountain Research Station, Fire

721 Sciences Laboratory (Producer). Available:

722 www.fs.fed.us/database/feis/animals/mammal/tahu/all.html [2021, April 22]. 
723 Svenning, J.-C., Normand, S. and Kageyama, M. (2008), Glacial refugia of temperate trees in

724 Europe: insights from species distribution modelling. Journal of Ecology, 96: 1117-1127.

725 Thorington, R. W., Koprowski, J. L., Steele, M. A., \& Whatton, J. F. (2012). Squirrels of the 726 world. Baltimore: The John Hopkins University Press.

727 Vahle, J. R., \& Patton, D. R. (1983). Red Squirrel Cover Requirements in Arizona Mixed

728 Conifer Forests. Journal of Forestry, 14-22.

729 Villette, P., Krebs, C.J. \& Jung, T.S. Evaluating camera traps as an alternative to live trapping

730 for estimating the density of snowshoe hares (Lepus americanus) and red squirrels (Tamiasciurus

731 hudsonicus). Eur J Wildl Res 63, 7 (2017). https://doi.org/10.1007/s10344-016-1064-3 


\section{FIGURE CAPTIONS}

733 Figure 1: Research area with trail system

734 Figure 2: Discrete midden

735 Legend: The cone debris forms one midden, no other debris accumulations are visible.

736 Figure 3: Diffuse midden

737 Legend: Several smaller piles of cone debris are located close to each other.

738 Figure 4: Pilot midden cruising survey in 2016 and 2017

739 Legend: The conducted survey of squirrel middens in 2016 is shown in red. The green markers

740 show middens that were still present one year later.

741 Figure 5: Middens and survey route within the research area

742 Legend: The white line indicates the survey route taken whereas the buffer around shows the

743 average visibility. The survey route was adjusted to visibility conditions.

744 Figure 6: Flow chart of the data analysis

745 Legend: The flow chart represents the workflow which resulted in the distribution model. It

746 shows starting data sets (Euclidean distances, LIDAR imagery and presence points), the analysis

747 steps and the final compiling of the midden distribution model.

748 Figure 7: Binary map showing areas where squirrels are present or absent based on the RIO

749 Legend: This map shows the predicted presence distribution in green which contains 95\% of

750 presence occurrences (midden). 
751 Figure 8: Predictive map of the predicted relative index of occurrence of squirrel midden within

752 the research area

753 Legend: The map shows the prediction of squirrel midden occurrence. The red areas have a high

754 probability of occurrence whereas the areas in green show low to no probability of occurrence.

755 The trails are clearly visible as well as the open area (North-East of the research area).

756 Figure 9: Partial dependence plot for canopy height [m]

757 Legend: The blue line indicates the likelihood of midden occurrence based on the canopy height.

758 Canopy below ca. 9m has a negative impact on midden occurrence and canopy above that level

759 vice versa.

760 Figure 10: Partial dependence plot of the distance to trails [m]

761 Legend: The blue line indicates the likelihood of midden occurrence based on the distance to

762 trails. A distance below ca. 10m has a negative impact on midden occurrence and a distance

763 above that level vice versa until a distance of $30 \mathrm{~m} .30 \mathrm{~m}-50 \mathrm{~m}$ distance to the trails has a

764 negative effect on midden occurrence again.

765 Figure 11: Partial dependence plot for canopy density, ranging from 0 (no trees; $0 \%$ ) to 1 (very

766 high canopy density, 100\%)

767 Legend: The blue line indicates the likelihood of midden occurrence based on the canopy

768 density. A canopy density below ca. 45\% has a negative impact on midden occurrence and

769 canopy density above that level vice versa, with a rising probability of occurrence for rising

770 canopy density.

771 Figure 12: Partial dependence plot for the distance from Smith lake [m] 
772 Legend: The blue line indicates the likelihood of midden occurrence based on the distance to

773 trails. A distance below ca. $250 \mathrm{~m}$ has a positive impact on midden occurrence and a distance

774 above that level vice versa. The closer to the lake, the higher is the probability of midden

775 occurrence. 
Figure 1

Research area with trail system

The research area is enclosed by the green line whereas the white line shows frequently used trails.

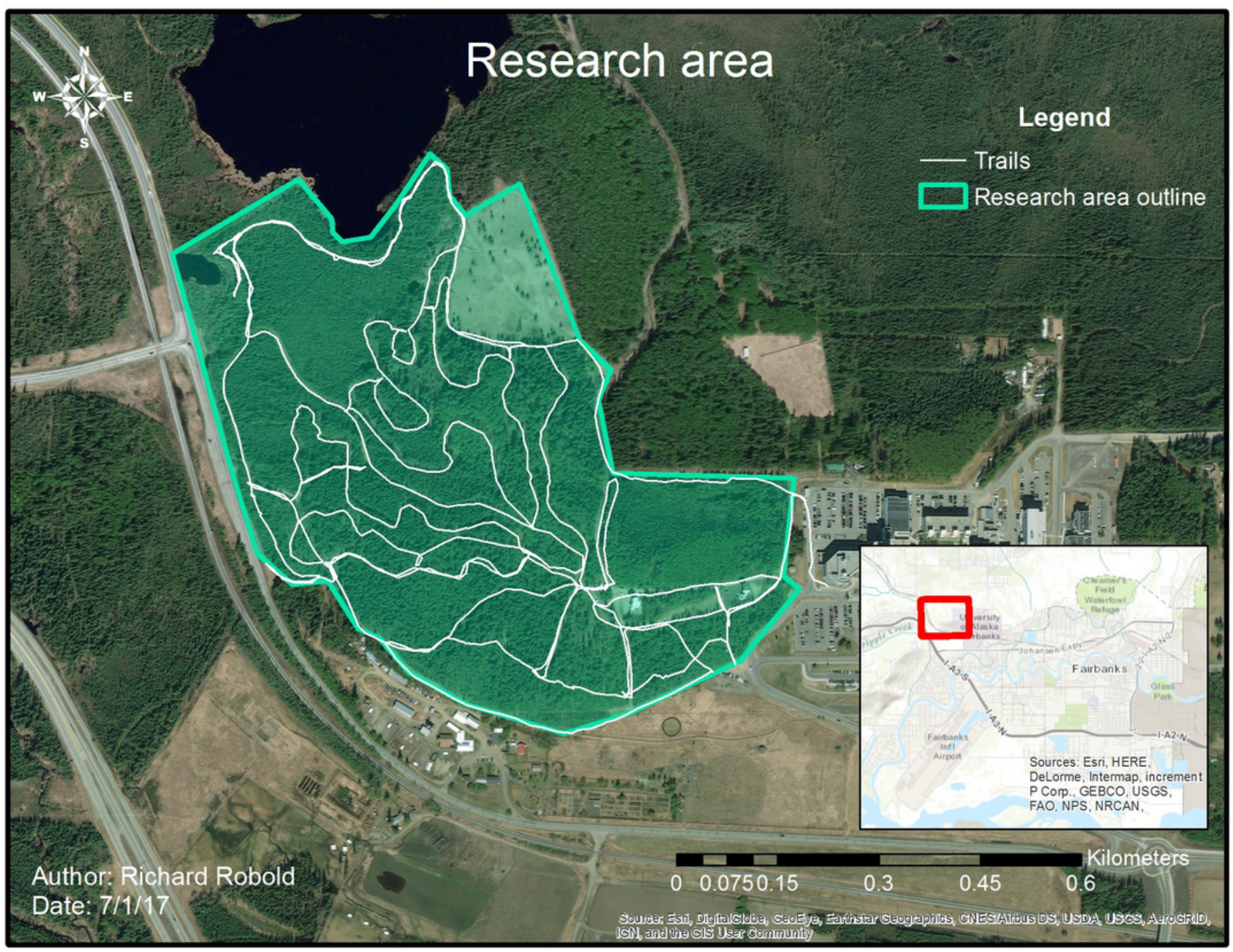


Figure 2

Discrete midden

The cone debris forms one midden, no other debris accumulations are visible.

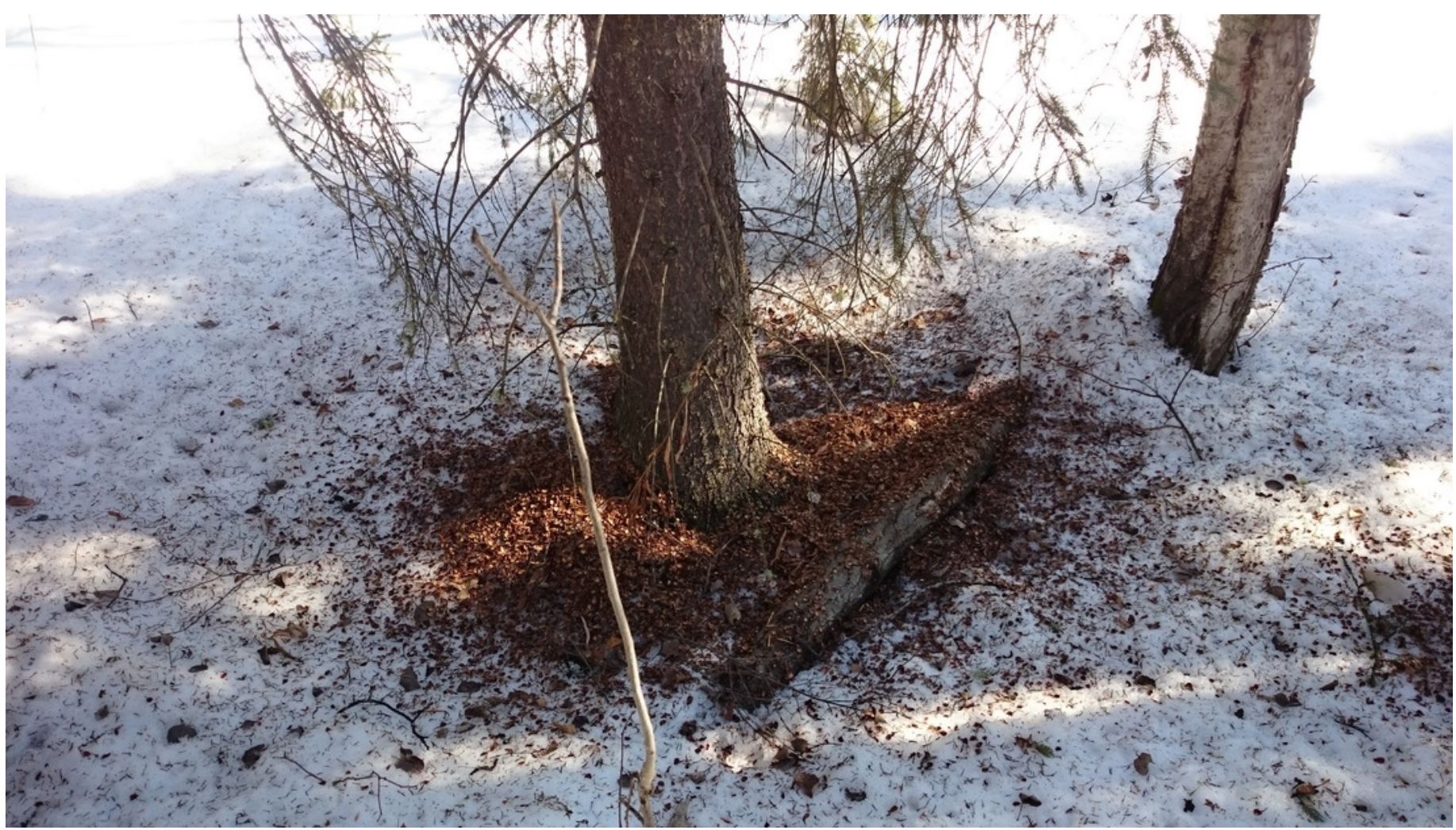




\section{Figure 3}

Diffuse midden

Several smaller piles of cone debris are located close to each other.

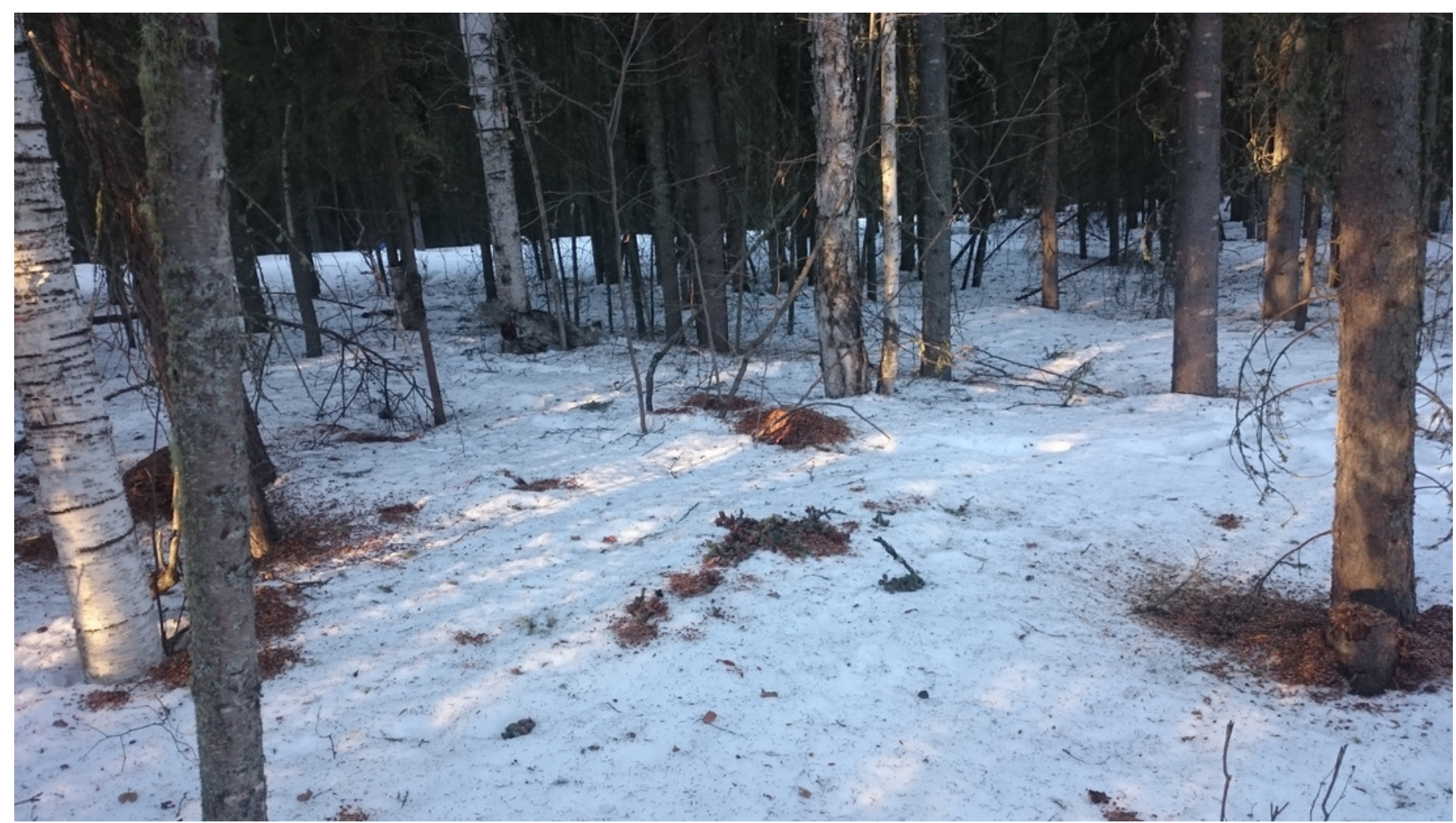


Figure 4

Pilot midden cruising survey in 2016 and 2017

The conducted survey of squirrel middens in 2016 is shown in red. The green markers show middens that were still present one year later.

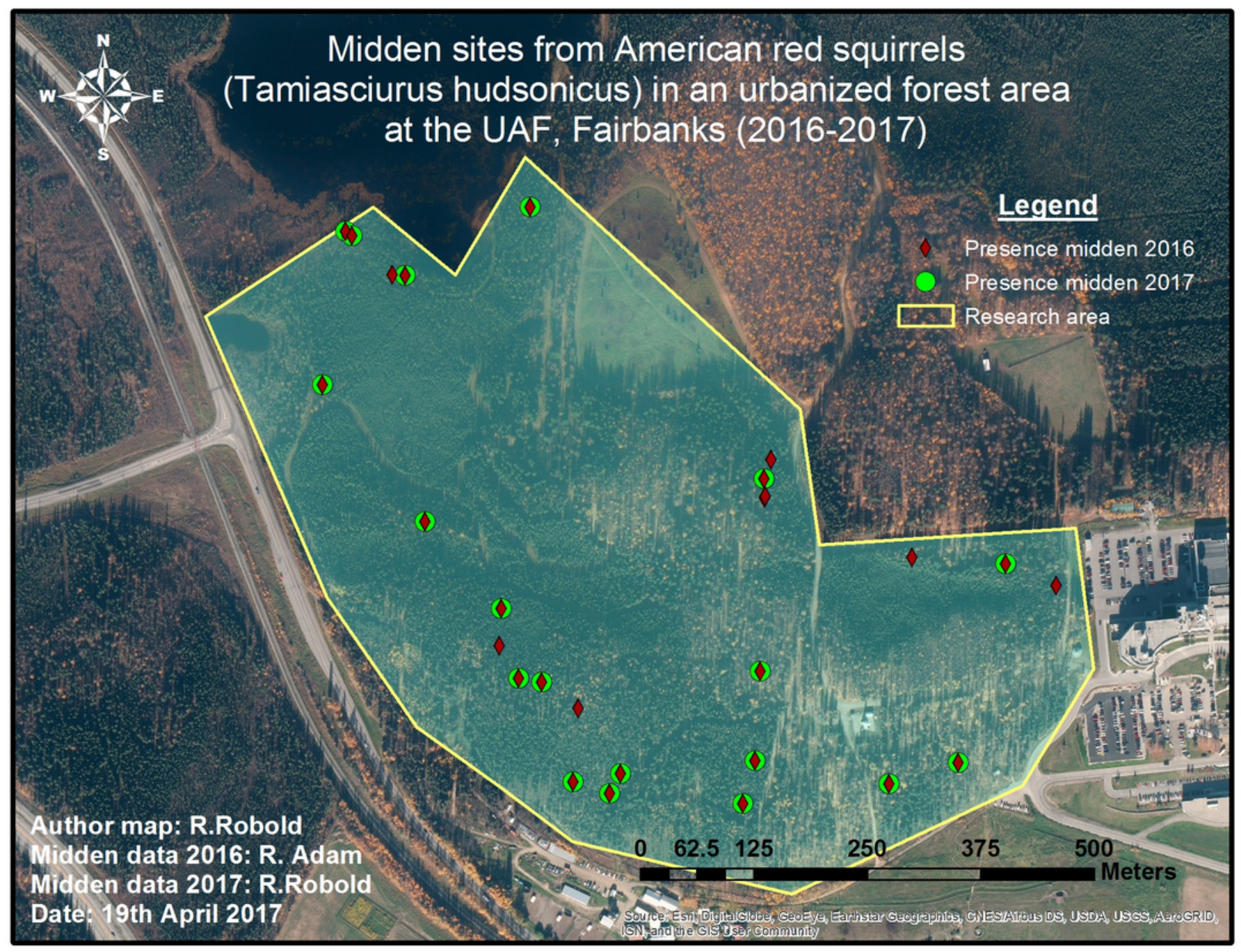




\section{Figure 5}

Middens and survey route within the research area

The white line indicates the survey route taken whereas the buffer around shows the average visibility. The survey route was adjusted to visibility conditions.

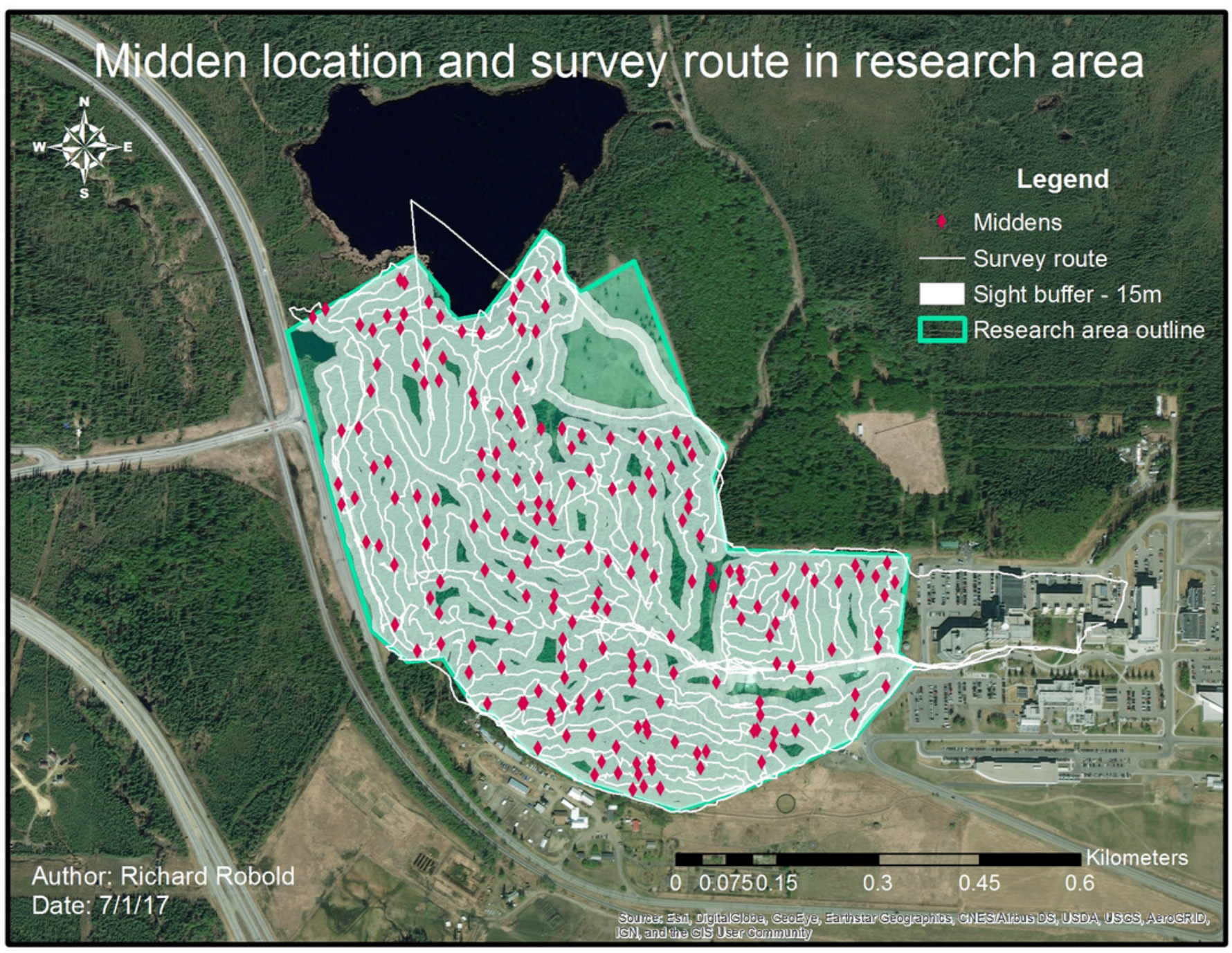


Figure 6

Flow chart of the data analysis

The flow chart represents the workflow which resulted in the distribution model. It shows starting data sets (Euclidean distances, LIDAR imagery and presence points), the analysis steps and the final compiling of the midden distribution model.

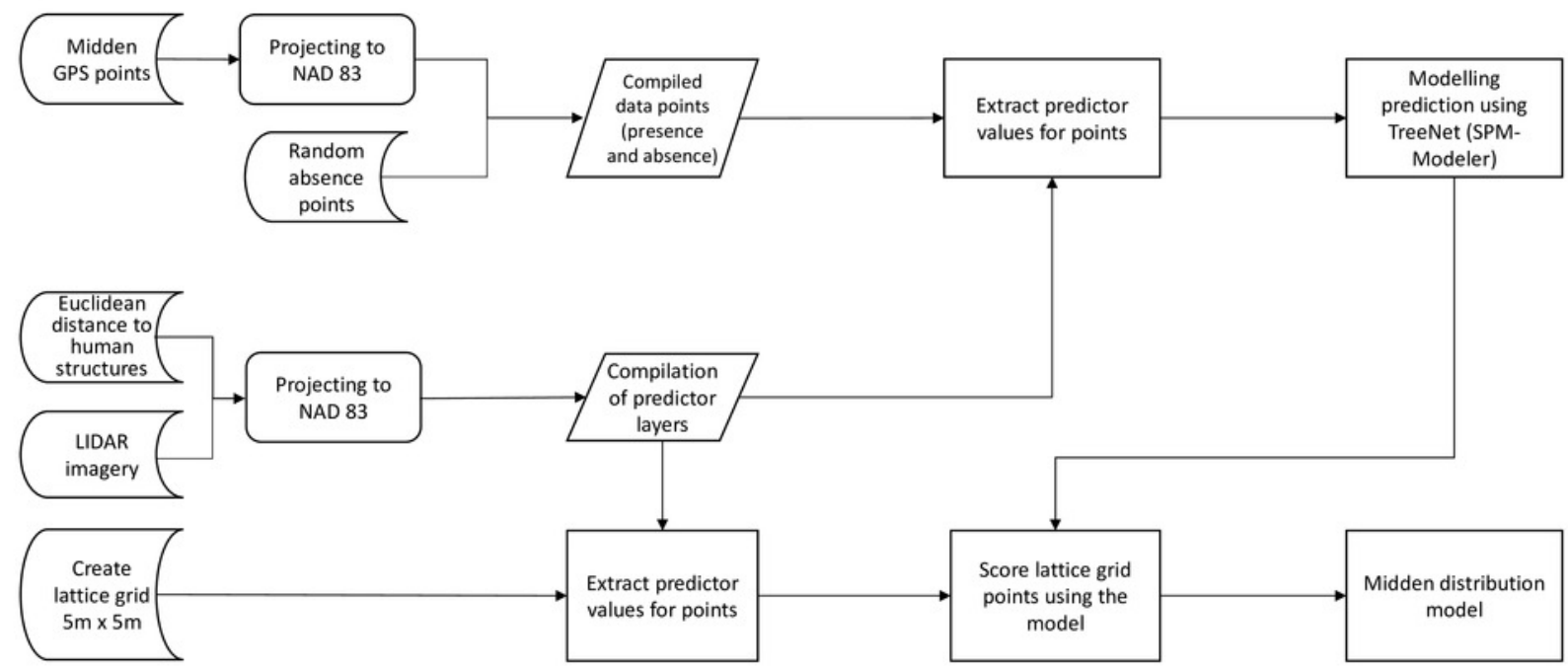




\section{Figure 7}

Binary map showing areas where squirrels are present or absent based on the RIO

This map shows the predicted presence distribution in green which contains 95\% of presence occurrences (midden).

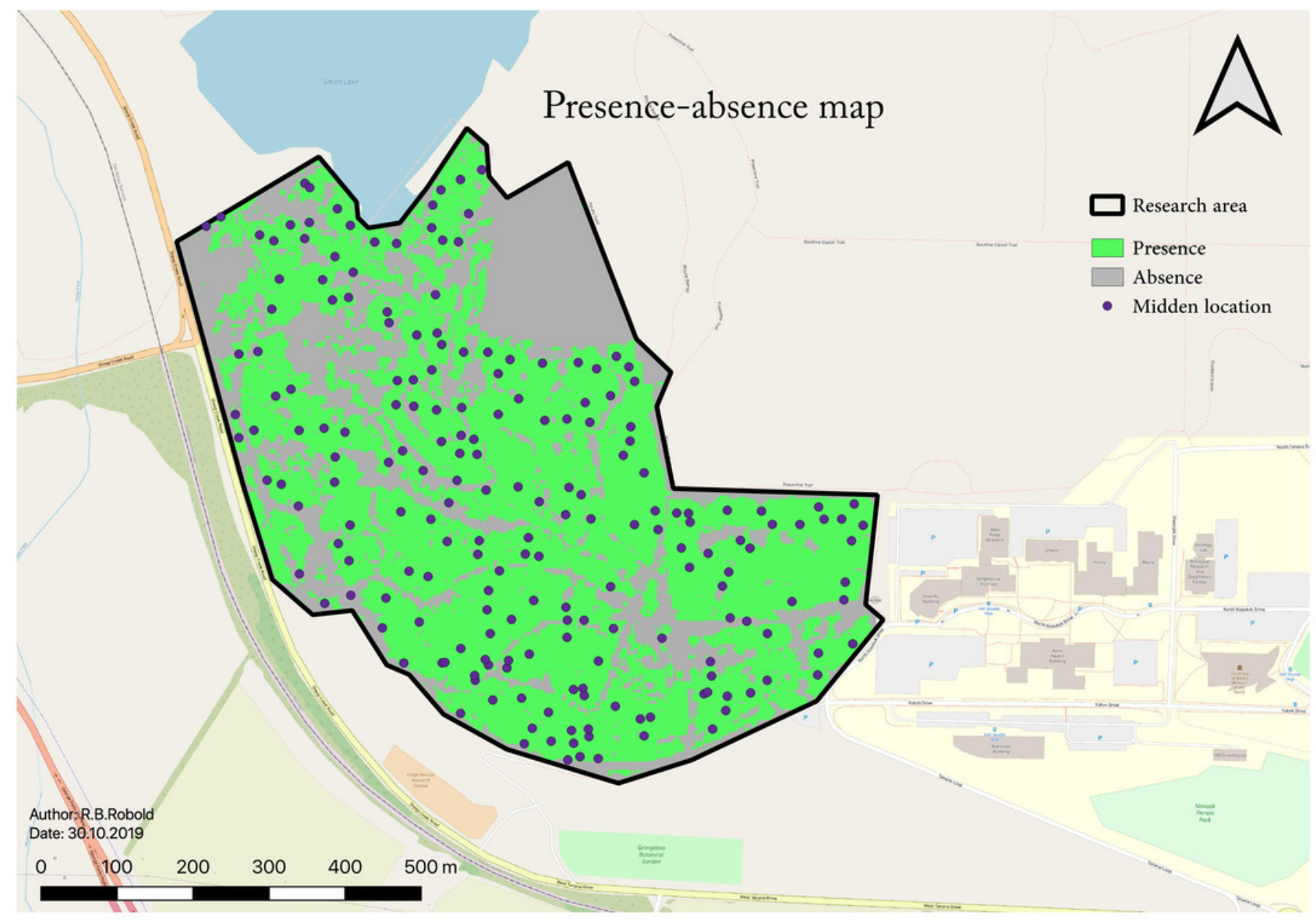




\section{Figure 8}

Predictive map of the predicted relative index of occurrence of squirrel midden within the research area

The map shows the prediction of squirrel midden occurrence. The red areas have a high probability of occurrence whereas the areas in green show low to no probability of occurrence. The trails are clearly visible as well as the open area (North-East of the research area).

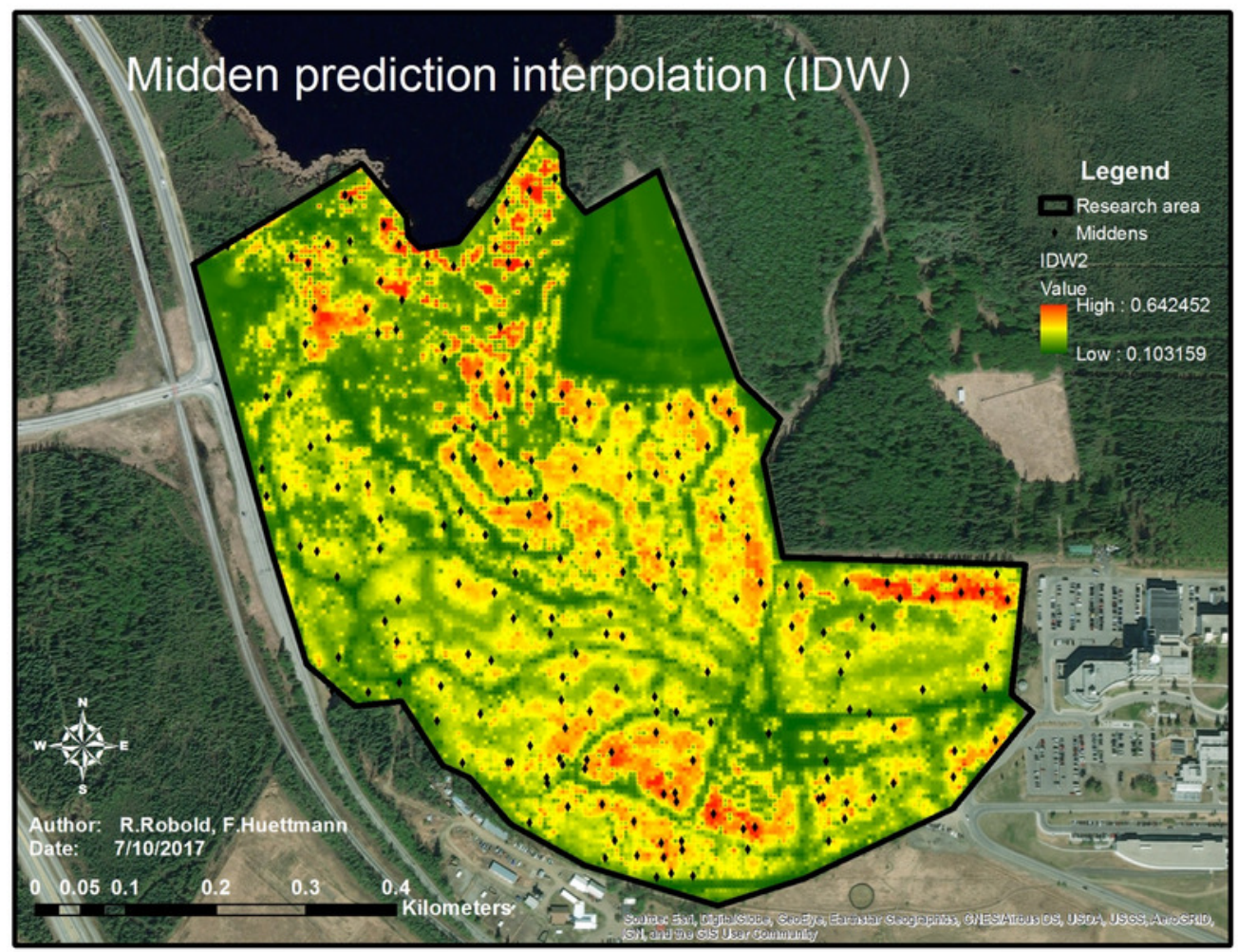


Figure 9

Partial dependence plot for canopy height [m]

The blue line indicates the likelihood of midden occurrence based on the canopy height.

Canopy below ca. $9 m$ has a negative impact on midden occurrence and canopy above that level vice versa.

One Predictor Dependence For PRESENCE

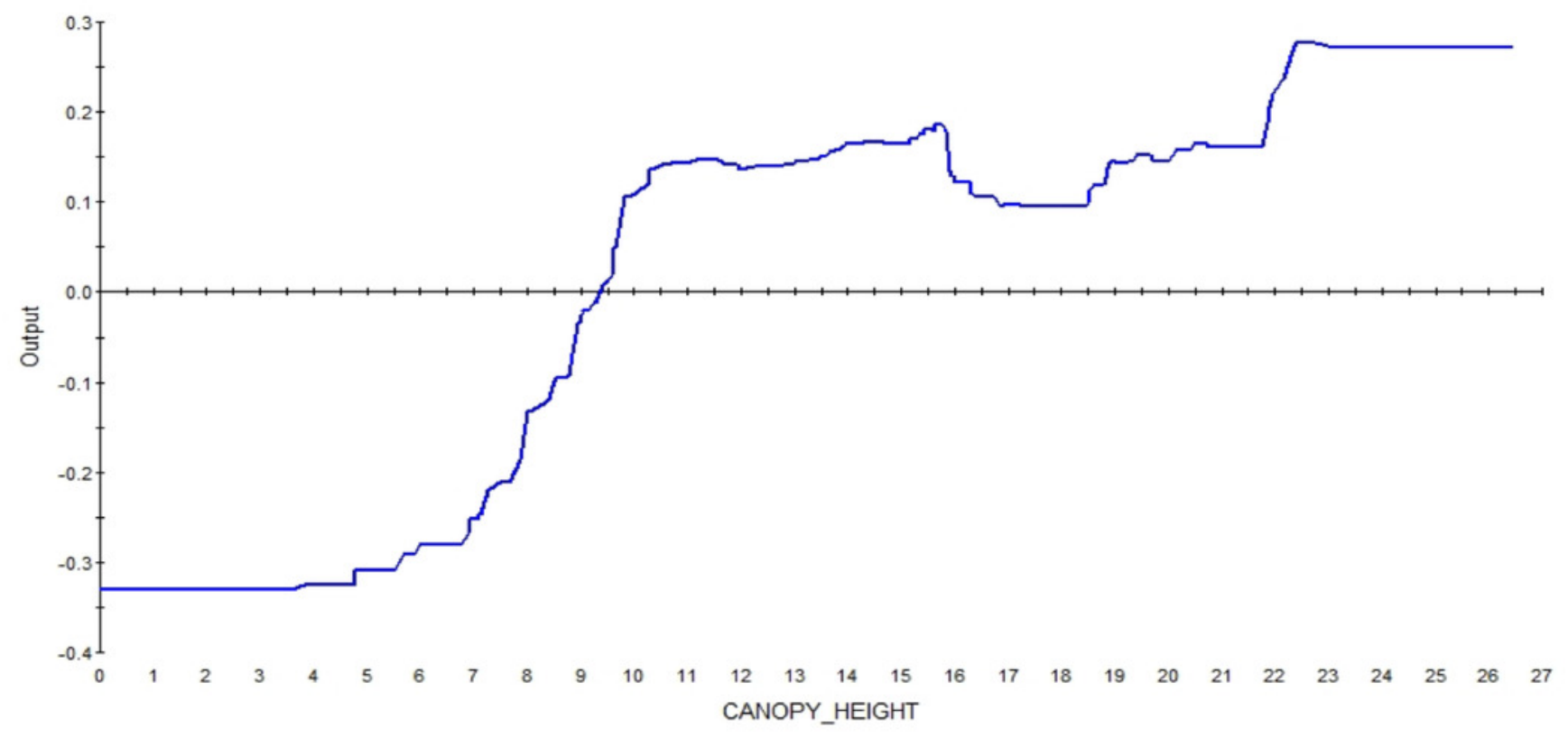




\section{Figure 10}

Partial dependence plot of the distance to trails [m]

The blue line indicates the likelihood of midden occurrence based on the distance to trails. $A$ distance below ca. $10 \mathrm{~m}$ has a negative impact on midden occurrence and a distance above that level vice versa until a distance of $30 \mathrm{~m}$. 30m - 50m distance to the trails has a negative effect on midden occurrence again.

One Predictor Dependence For PRESENCE

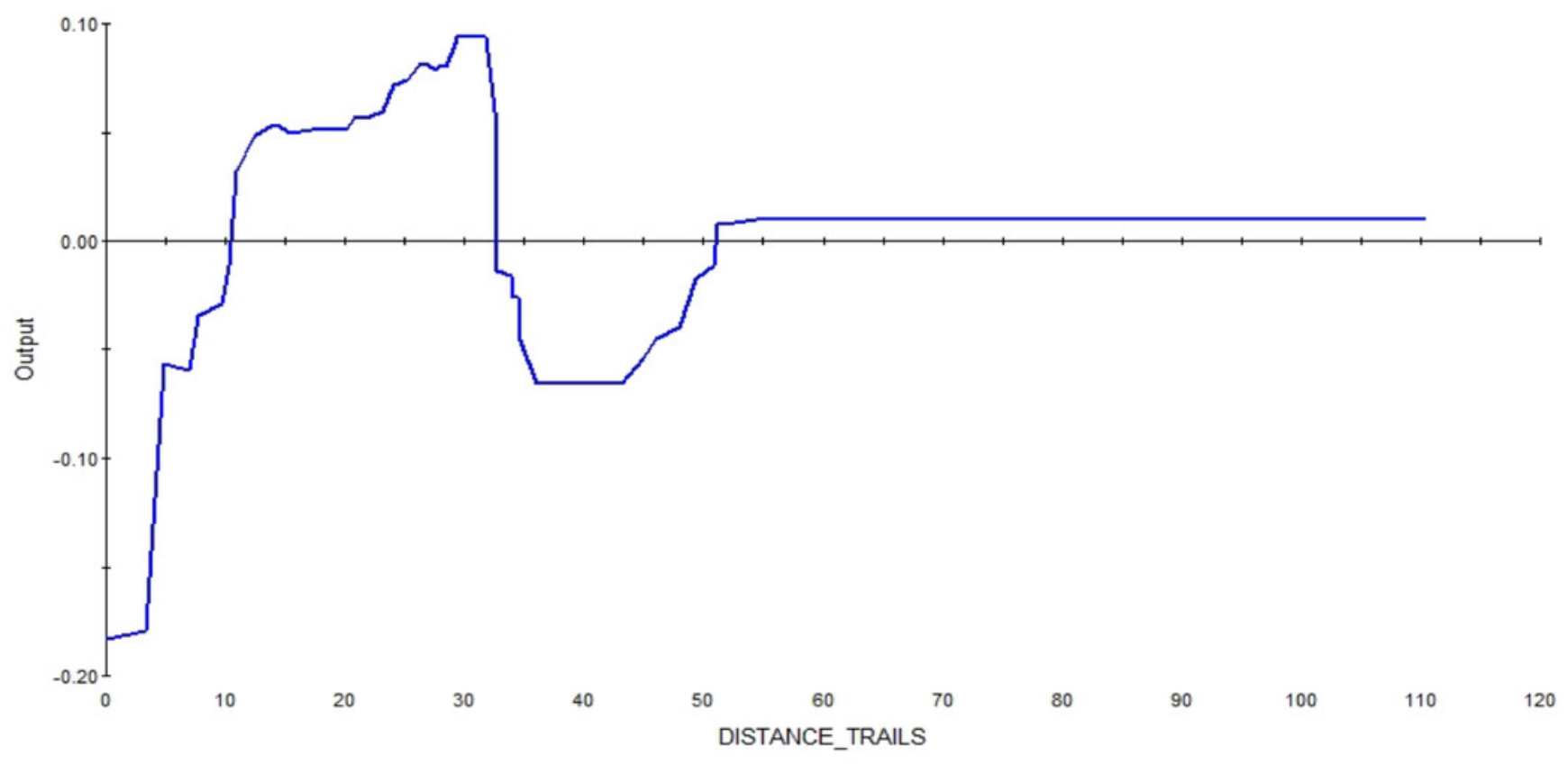


Figure 11

Partial dependence plot for canopy density, ranging from 0 (no trees; $0 \%$ ) to 1 (very high canopy density, 100\%)

The blue line indicates the likelihood of midden occurrence based on the canopy density. A canopy density below ca. 45\% has a negative impact on midden occurrence and canopy density above that level vice versa, with a rising probability of occurrence for rising canopy density.

One Predictor Dependence For PRESENCE

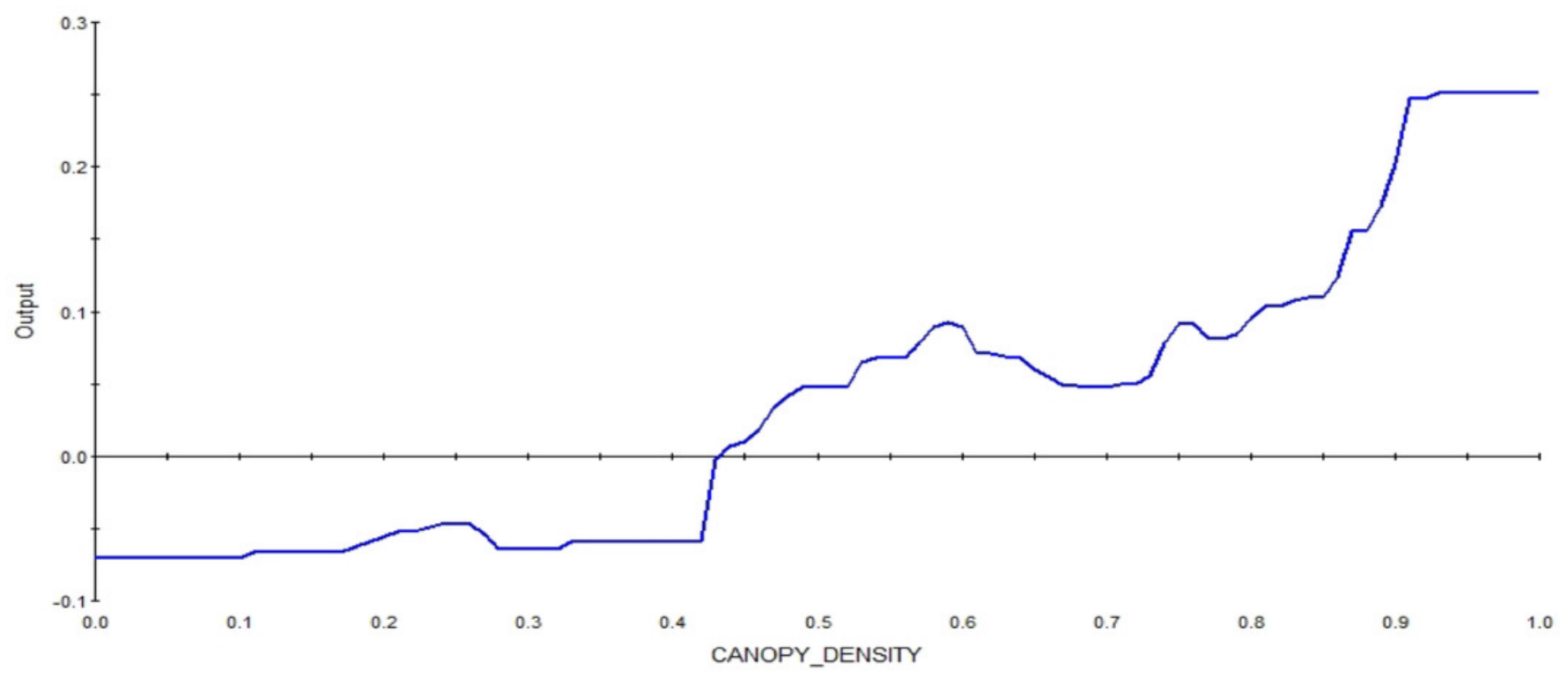


Figure 12

Partial dependence plot for the distance from Smith lake [m]

The blue line indicates the likelihood of midden occurrence based on the distance to trails. A distance below ca. $250 \mathrm{~m}$ has a positive impact on midden occurrence and a distance above that level vice versa. The closer to the lake, the higher is the probability of midden occurrence.

One Predictor Dependence For PRESENCE

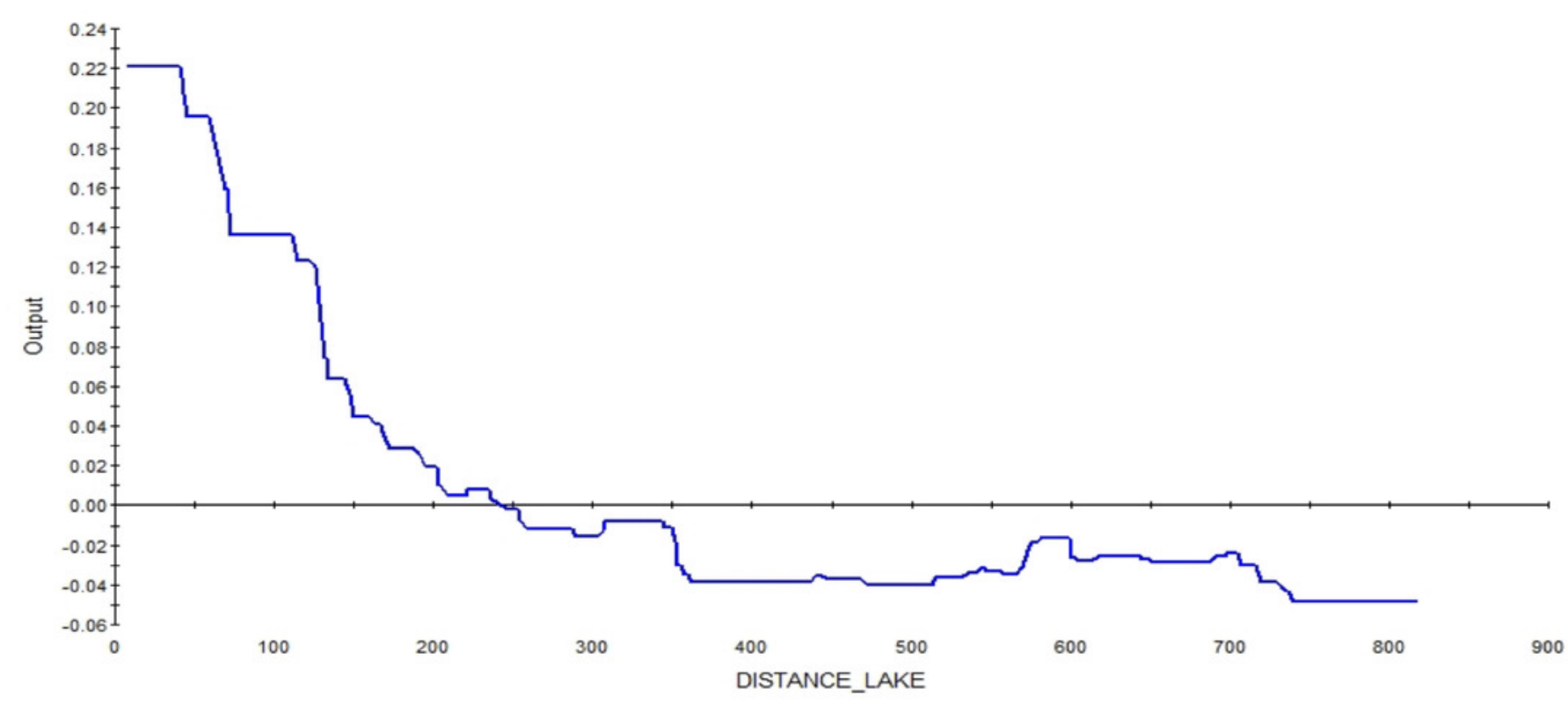




\section{Table 1 (on next page)}

Score of predictor importance

The table shows the importance of the single predictors on a scale from 100 (most important) to 0 (relative to the most important factor). 


\section{TABLES}

2 Table 1: Score of predictor importance

3

\begin{tabular}{ll} 
Predictor & Score \\
Canopy height & 100.00 \\
\hline Distance to trails & 73.37 \\
\hline Canopy density & 71.02 \\
\hline Distance to lake & 69.33 \\
\hline Aspect & 60.18 \\
\hline Distance to highway & 57.37 \\
\hline Distance to buildings & 53.06 \\
\hline Distance to the dog & 46.31 \\
\hline trail & \\
\hline Elevation & 44.56 \\
\hline Slope & \\
\hline
\end{tabular}

4 Legend: The table shows the importance of the single predictors on a scale from 100 (most

5 important) to 0 (relative to the most important factor). 